\title{
CSHP Professional Practice Conference 2017: Poster Abstracts / Conférence sur la pratique professionnelle 2017 de la SCPH : Résumés des affiches
}

Facilitated Poster Sessions: Discussion of original research and pharmacy practice projects

Séance animée de présentations par affiches: Discussions sur des projets de recherche originale et des projets dans le domaine de la pratique pharmaceutique

\section{Sunday, February 5, $2017 \bullet$ Dimanche 5 février 2017}

\section{Medication Effectiveness / Clinical Pharmacy Services}

1. Effect of Glucagon-Like Peptide-1 Receptor Agonists on All-Cause Mortality and Cardiovascular Outcomes: A Meta-Analysis

2. Clinical Pharmacy Services in Canadian Pediatric Intensive Care Units

3. Pharmacist Role in the Emergency Department at Two Urban Acute Care Sites

4. Physical Assessment Training to Enhance Pharmacist Confidence in Medication Management

5. Following-Up in Smoking Cessation - What Do Patients Want?

6. Pharmacist Education and Telephone Follow-Up after Hospitalization for an Acute Coronary Event: The Assessment of Cardiology Peri-Discharge Counseling (ACDC) Pilot Study

7. Evaluation of Melatonin Use for the Management of Insomnia in Elderly Inpatients in a Community Hospital

8. Evaluation of the Standardization of Transfer of Accountability between Pharmacists

9. Evaluation of the Standardization of Pharmacist Involvement in Discharge Medication Reconciliation

10. Nabilone for Prevention of Acute Chemotherapy-Induced Nausea and Vomiting in Children: A Single Centre Retrospective Review

11. Validation of Patients' Response to the Hospital-Consumer Assessment of Healthcare Providers and Systems (H-CAHPS) Survey Question: "During Your Hospital Stay, Did You Meet with a Pharmacist?"

Antimicrobial Stewardship / Medication Safety

1. Preventable Medication Errors: Solid Oral Dosage Forms of Diltiazem

2. A Systematic Review of Antimicrobial Stewardship Interventions in the Emergency Department

3. Development of Standardized Hospital-Wide Inpatient Insulin Order Sets for Implementation in an Academic Tertiary Care Centre

4. Determination of Fosfomycin Susceptibility in Multi-Drug Resistant Enterobacteriaceae spp. and Vancomycin-Resistant Enterococci Urinary Isolates

5. Vancomycin Trough Concentrations and Clinical Outcomes in Non-Deep Seated Infections - A Retrospective Study

6. Effect of an Intervention to Decrease Antibiotic Use in Asymptomatic Bacteriuria in an Acute Care Setting

7. Aripiprazole Use and the Occurrence of Rhabdomyolysis

8. Needs Assessment for Antimicrobial Stewardship in a Rehabilitation Hospital: A Retrospective, Descriptive Study

9. Effects of Reducing the Urine Alkalinisation Threshold Associated with High-Dose Methotrexate Administration

10. Measuring Potential Occupational Exposure to Vaporized and Nebulized Finasteride

11. Prevalence of Penicillin Allergy Verified by Skin Testing in Patients Reporting Allergy to Penicillin

Medication Use Optimization / Compounding

1. Medication Adherence Assessment of Patients in a Cardiac Rehabilitation Clinic

2. Target Dose Achievement of Evidence-Based Medications in Patients with Heart Failure with Reduced Ejection Fraction Attending a Heart Failure Clinic

3. Keeping Mom and Baby Healthy - An Immunization Pilot Project

4. Identifying Care Gaps in the Electronic Discharge Medication Reconciliation Process at an Acute Care Facility
5. Stability of a Simple Finasteride $0.33 \mathrm{mg} / \mathrm{mL}$ Suspension Using Tablets in Water and an Oral Mix Vehicle

6. Establishing an Environmental Monitoring Program for Viable Airborne Particles in Pharmacy Sterile Rooms

7. Stability of 0.2 and $10 \mathrm{mg} / \mathrm{mL}$ Hydromorphone Solutions in CADD® Reservoirs, PVC and Ethylene/Propylene Co-Polymer (PAB®) Bags at Room Temperature $\left(23^{\circ} \mathrm{C}\right)$

8. Stability of $0.05 \mathrm{mg} / \mathrm{mL}$ Sufentanil Solutions in CADD® Reservoirs, PVC Containers, Ethylene/Propylene Co-Polymer (PAB $\left.{ }^{\circ}\right)$ Bags and Syringes at Room Temperature $\left(23^{\circ} \mathrm{C}\right)$

9. Stop, Drop, and Shake: Developing a Finasteride Oral Liquid Preparation in Distilled Water or Oral Mix Vehicle Using Whole Uncrushed Tablets

10. A Retrospective Audit of Medication Prescribing Practices: A Quality Improvement Initiative

\section{Monday, February 6, 2017 • Lundi 6 février 2017}

Medication Effectiveness / Clinical Pharmacy Services

1. Near-Peer Facilitation in Delivering Pharmacy Practice Skills for Pharmacy Students

2. Ketamine for the Treatment of Acute Pain in the Pre-Hospital and Emergency Department Setting: A Systemic Review

3. How Do Patient, Pharmacist and Interprofessional Stakeholder Perspectives on Clinical Pharmacy Key Performance Indicators Compare across Canada?

4. Preceptor/Assessor Training Regarding Use of a Standard Assessment Tool for Field-Based Pharmacy Education

5. Hospital Pharmacists' Skills Development Grid and Job Standards Timeline: Description of Development and Use a at Pediatric Tertiary Care Institution

6. Aide humanitaire et contribution des pharmaciens : une revue de littérature

7. Evaluation of Medication Reconciliation by Pharmacy Technicians in the Emergency Department

8. Travail de proximité des pharmaciens dans les groupes de médecine de famille : l'impact sur la collaboration et la communication interprofessionnelle

9. Patient Perspectives on Clinical Pharmacy Key Performance Indicators: A Qualitative Study

10. Creation and Implementation of a Program-Wide Standardized Clinical Workload Reporting System

11. Going Beyond the Inpatient Role: An Evaluation of Clinical Pharmacy Services in a Pediatric Outpatient Clinic Setting

Antimicrobial Stewardship / Medication Safety

1. Thrombocytopenia during Treatment with Ceftolozane/Tazobactam

2. Medication Incidents Involving Metformin: A Multi-Incident Analysis

3. Managing Warfarin-Rifampin Drug Interaction: A Case Series

4. A Prospective Audit of Medication Preparation and Administration Practices: A Quality Improvement Initiative

5. Relationship between Additional Prescribing Authorization Rates and Work Environment Variables among Clinically Deployed Hospital Pharmacists

6. Review of Immunosuppression Withdrawal after Renal Transplant Failure

7. Pénuries des médicaments au Canada en 2016 : une problématique toujours d'actualité

8. Médicaments de niveau d'alerte élevé : profil des stratégies utilisées au sein d'un centre hospitalier universitaire canadien

9. A Case Series of Patients Using Naloxegol to Reduce Time to Gastrointestinal Recovery Following Surgery

10. Needs Assessment for Antimicrobial Stewardship in an Acute and Complex Care Hospital Specializing in Orthopaedic Surgery: A Retrospective Descriptive Study

11. Development of an Algorithm for a Systematic Evaluation and Classification of Hazardous Drugs 
Medication Use Optimization / Compounding

1. Long-Term Benzodiazepine Use and Discontinuation: Exploring Hemodialysis Patients' Perspectives

2. Benzodiazepine and Sedative-Hypnotic Drug Use in Nova Scotia Hospitals: A Point Prevalence Survey

3. What's Happening? Patient Access to Compounded Drugs in Paediatrics after Discharge from a Tertiary Center: A Research Team's Perspective

4. Validation des ordonnances : existe-t-il un ordre optimal ? Avis des chefs de départements de pharmacie

5. Comparaison du cadre juridique et des prises de position des agences réglementaires sur les produits biologiques ultérieurs : que doivent savoir les pharmaciens canadiens?
6. Development and Validation of a Clinical Decision Tool for Blood Pressure Management in Patients on Hemodialysis

7. Compounding of Oral Drugs for Children in a Canadian Pediatric Academic Health Centre

8. Optimizing Proton Pump Inhibitor Therapy in Primary Care: A Pilot Study Evaluation of a Patient Directed Intervention

9. Stability of 10 and $50 \mathrm{mcg} / \mathrm{mL}$ Fentanyl Solutions in CADD® Reservoirs, PVC Containers and Ethylene/Propylene Co-Polymer (PAB®) Bags at Refrigerated $\left(4^{\circ} \mathrm{C}\right)$ and Room Temperature $\left(23^{\circ} \mathrm{C}\right)$

10. Applying the Proton Pump Inhibitor Deprescribing Algorithm in Stable Patients in a Community Hospital

The texts of poster abstracts are published exactly as submitted by the authors and have not undergone any copyediting by the Canadian Journal of Hospital Pharmacy. I Le Journal canadien de la pharmacie hospitalière n’a pas soumis le texte des résumés des affiches à une révision linguistique et les publie ici tels que remis par les auteurs.

\section{Effect of Glucagon-Like Peptide-1 Receptor Agonists on All-Cause Mortality and Cardiovascular Outcomes: A Meta-Analysis}

Peterson $S^{1}$, Barry $A^{1,2}$

${ }^{1}$ Faculty of Pharmaceutical Sciences, University of British Columbia, Vancouver, $B C$

${ }^{2}$ Chilliwack General Hospital, Lower Mainland Pharmacy Services, Chilliwack, $B C$

Background: Cardiovascular disease is the leading cause of death in patients with type 2 diabetes. Glucagon-like peptide-1 (GLP-1) receptor agonists have been shown to reduce glycosylated hemoglobin and promote weight loss, but their impact on clinically relevant outcomes is unknown.

Objective: To assess the impact of GLP-1 agonist therapy, compared to placebo, on all-cause and cardiovascular mortality, nonfatal myocardial infarction (MI), nonfatal stroke, and hospitalizations for heart failure in patients with type 2 diabetes.

Methods: EMBASE, MEDLINE, and CENTRAL were systematically searched (to September 2016) for randomized, placebo-controlled trials of at least 1 year in duration that compared any GLP-1 agonist to placebo in type 2 diabetic patients. Both authors independently completed the literature search, data extraction, and risk of bias assessment. For each outcome of interest, a risk ratio (RR) and 95\% confidence interval (CI) were calculated using a Mantel-Haenszel random effects model.

Results: Eight double-blind trials (3 albiglutide, 2 lixisenatide, 2 liraglutide, 1 semaglutide) consisting of 21,135 patients were included. Most patients had, or were at high risk for, cardiovascular disease. Follow-up ranged from 1-3.8 years. Trials contributing the majority of data were deemed to have a low risk of bias. All-cause mortality was reduced by $11 \%$ in patients receiving a GLP-1 agonist compared to placebo (5.98\% versus $7.30 \%$, RR 0.89 , 95\% CI 0.81-0.99). There was no statistically significant difference between groups with respect to cardiovascular death (RR 0.88, 95\% CI 0.75-1.03), nonfatal MI (RR 0.92 , 95\% CI 0.80-1.06), nonfatal stroke (RR 0.89, 95\% CI 0.72-1.09), or hospitalizations for heart failure (RR $0.93,95 \%$ CI 0.81-1.06).

Conclusion: GLP-1 agonists, when compared to placebo, reduced all-cause mortality in type 2 diabetic patients at high risk of cardiovascular disease. However, they did not impact cardiovascular-related outcomes including death from cardiovascular causes, nonfatal MI, nonfatal stroke, or hospitalizations for heart failure.

\section{Clinical Pharmacy Services in Canadian Pediatric Intensive Care Units}

Vaninetti $G^{1}$, Chan $A^{2}$, Kraft $T^{3}$, Duffett $M^{4}$

${ }^{1} I$ WK Health Centre, Halifax, NS

${ }^{2}$ Stollery Children's Hospital, Edmonton, $A B$

${ }^{3}$ Alberta Children's Hospital, Calgary, $A B$

${ }^{4}$ McMaster Children's Hospital and McMaster University, Hamilton, ON

Background: Pharmacists are essential members of the Pediatric Intensive Care Unit (PICU) care team, but training, experience, roles, and staffing models vary.

Objective(s): Our objective was to describe clinical pharmacy services in Canadian PICUs: staffing levels, staffing models, pharmacy services, training and experience.

Methods: A PICU pharmacist at each centre used a standard form to describe their unit, staffing and pharmacists. Participation was voluntary and collected data was de-identified.

Results: Thirteen of 16 (81\%) PICUs from 7 provinces participated. Clinical pharmacist services are provided 7 days/week at $2(15 \%)$ sites. Three (23\%) PICUs have a satellite pharmacy. Two (15\%) PICUs have pharmacists as members of Code Team. The median number of full time equivalents (FTE) per PICU was $1(\min 0.4, \max 4)$ and the median FTE per PICU bed was 0.07 ( $\min 0.03$, max 0.33). Seven (54\%) PICUs provide clinical coverage when pharmacist is absent for vacation/illness. Thirty-three pharmacists practice in these units (median 2.5 per PICU, maximum 6) and spend a median of $40 \%$ of their time in the PICU. Thirty (91\%) reported working full-time. Thirty-two (97\%) have responsibilities outside of PICU, most frequently central pharmacy (72\%) or NICU (25\%). Pharmacists reported a median of 10 years of clinical experience and a median of 6 years in the PICU. Twenty-one (64\%) pharmacists are residency trained, $6(18 \%)$ have a post-graduate PharmD, and $4(12 \%)$ are board certified. Twelve (36\%) have a university faculty appointment.

Conclusion: There is significant variability in how clinical pharmacy services are provided in Canadian PICUs, particularly coverage in the absence of the PICU pharmacist, allocated FTE per patient bed, and level of experience. This report provides a baseline of current pharmacy services as health authorities, management, practice leaders, professional associations, and frontline pharmacy staff work to ensure optimal patient care, research, and education. 


\section{Pharmacist Role in the Emergency Department at Two Urban Acute Care Sites}

\author{
Cummings $G^{1}$, Whitten $L^{2}$, Lee $K^{2}$ \\ ${ }^{1}$ Alberta Health Services, Pharmacy Services, Calgary, $A B$ \\ ${ }^{2}$ Alberta Health Services Calgary Zone Safe Clinical Practice Program, \\ Calgary, $A B$
}

Background: The Emergency Department (ED) is a high risk setting for medication errors and adverse drug events (ADE). A pharmacist can be a valuable team member to improve patient safety in the ED.

Description: In this pilot project, 2 pharmacists were hired to develop new clinical practices in the EDs of 2 urban acute care hospitals. The pharmacists provided direct patient care at full scope with a focus on 3 specialized service areas: anticoagulation management, antimicrobial stewardship and pain management.

Action: Pharmacist workload was documented and thematic analysis was performed of recorded clinical activities. Retrospective descriptive analysis was used to describe the role of the pharmacist in the ED. A staff satisfaction survey was also conducted to evaluate the awareness and utilization of the pharmacist among ED staff.

Evaluation: After 6 months, the pharmacists recorded being involved in the care of over 3100 patients. Initial patient assessment and formulating/implementing treatment plans were the top clinical activities performed. Thematic analysis described the pharmacists' involvement in identification, management and prevention of ADE, complex medication reconciliation, patient education, and seamless care. Seventy-five percent of survey respondents $(\mathrm{n}=147)$ reported either having consulted or received assistance from the ED pharmacist and $85 \%$ of respondents felt the pharmacist improved patient care. Pharmacist involvement in anticoagulation (39\%) and pain management services (36\%) were reported by staff as being underutilized. Fifty-four percent of ED staff utilized pharmacist prescribing in a targeted antimicrobial stewardship activity which they felt improved efficiency and safety of patient care.

Implications: This pilot project defined a role for clinical pharmacists in the ED. Defining the role of pharmacy technicians in ED and optimizing the capacity of the ED pharmacist are important next steps to continue to develop the practice area. Following the pilot project, permanent funding was obtained for the ED pharmacists.

\section{Physical Assessment Training to Enhance Pharmacist Confidence in Medication Management}

Cummings $G^{1}$, George-Phillips $K^{2}$, Lowerison $J^{1}$, Macek $P^{2}$, Mayo $P^{2}$, Picard $M^{3}$

${ }^{1}$ Alberta Health Services (AHS) Pharmacy Services, Calgary, $A B$

${ }^{2} A H S$ Pharmacy Services, Edmonton, $A B$

${ }^{3} A H S$ Pharmacy Services, Grande Prairie, $A B$

Background: Clinical pharmacists manage and monitor medication therapy as the primary focus of direct patient care. As an understanding of physical assessment (PA) findings is often required for medication monitoring, a working group was formed to develop and provide PA skills training for hospital-based pharmacists.

Description: A vital signs training module was developed for pharmacists in order to increase understanding of how to measure vital signs and apply these findings to medication monitoring. Vital signs assessment skills were felt to be broadly applicable to pharmacists in all practice settings.

Action: Over 12 months, a total of 49 pharmacists participated in a two-part module consisting of online self-study activities and a small group interactive workshop. Assessment of temperature, respiratory rate, pulse oximetry, heart rate and blood pressure were taught. The workshops were delivered via internet-based, interactive videoconferencing with experienced facilitators physically present at each workshop to provide demonstration and feedback to participants as they practiced PA techniques.

Evaluation: Module participants were invited to anonymously complete pre and post module surveys to measure their own confidence performing PA skills and application to their clinical practice. Participants ranked their confidence on a 4 point scale ranging from 'not confident' to 'very confident'. The number of pharmacists reporting being 'confident' or 'very confident' increased in all areas of evaluation from the pre to post module period. Confidence in measuring vital signs increased from $6.1 \%$ to $48.5 \%$, discussing vital signs finding with a physician or other health care provider increased from $30.3 \%$ to $93.6 \%$, and managing drug therapy based upon vital signs findings increased from $36.4 \%$ to $90.3 \%$.

Implications: This PA training opportunity increased the self-reported confidence of pharmacists in performing vital signs assessments, discussing results, and managing medication therapy based upon their findings. Further PA training opportunities for pharmacists should be explored and developed.

\section{Following-Up in Smoking Cessation - What Do Patients Want?}

Lui K, Han L, Lin M

Canadian Forces Health Services Group, Toronto, ON

Background: Despite evidence supporting the benefits of continued patient counselling in maintaining long-term smoking abstinence, there is limited data on specific follow-up interventions, their optimal frequency, and patient preferences in these regards. This limitation in data is also reflected in the discordance in reimbursement schedules and recommendations between provinces for pharmacy-based smoking cessation services. Existing recommendations were largely developed using a mix of clinical evidence and expert opinion, and does not account for patient preferences. An indexed literature search, to date, has not identified studies pertaining to patient preferences in smoking cessation follow-up.

Objective: This study aimed to examine preferences for smoking cessation follow-up amongst military members who sought health care professional assistance for smoking cessation.

Methods: Between June and August 2013, patients who initiated smoking cessation at Canadian Forces Base (CFB) Petawawa's weekly smoking cessation clinic were offered an anonymous survey which inquired about their preferences for follow-up. The survey used was developed collaboratively by a multidisciplinary team. It was subsequently reviewed by multidisciplinary clinicians, and pretested on lay CAF members, which included both smokers and non-smokers. Responses were collated at CFB Petawawa and descriptive analysis was done using Excel.

Results: [see Abstract Appendix, details below]

Conclusion: In the presence of adequate initial patient education, most patients initiating smoking cessation preferred for follow-up to be at a frequency of every 2-4 weeks, with duration of 1-10 minutes each time. The preferred methods for contact were cell phone and email. Consideration of patient preferences in continued patient counseling recommendations may enhance the ability of clinicians to develop of therapeutic alliances and further improve clinical outcomes in smoking cessation overall.

For the table that goes with this abstract, please see Abstract Appendix, available at www.cjhp-online.ca/index.php/cjhp/issue/view/119/ show Toc 


\section{Pharmacist Education and Telephone Follow-Up after Hospitalization for an Acute Coronary Event: The Assessment of Cardiology Peri-Discharge Counseling (ACDC) Pilot Study}

De Guzman $M^{1}$, Carter $M^{1}$, Gorman $S K^{1,2}$, Slavik $R S^{1,2}$, Rawnsley $D^{1}$ ${ }^{1}$ Interior Health Authority - Kelowna General Hospital, Kelowna, BC ${ }^{2}$ University of British Columbia, Vancouver, $B C$

Background: Poor adherence to Acute Coronary Syndrome (ACS) medications is associated with increased 1-year mortality. Patients' beliefs about medications were identified as a key modifiable barrier to adherence.

Objectives: To evaluate the feasibility of a pharmacist intervention to improve adherence that targets patients' beliefs about medications, the feasibility of conducting a randomized trial to assess this intervention, and this intervention's effect on patient beliefs and adherence.

Methods: This was a post-test only, with non-equivalent groups pilot study. Participants were adult inpatients with ACS to be discharged home. Intervention group participants received pharmacist discharge counseling and telephone follow-up 1 week post-discharge. Both intervention and control participants received usual care discharge education by nurses. Primary outcomes include recruitment rate, attrition rate and duration of pharmacist intervention. Secondary outcomes include Beliefs about Medicines Questionnaire (BMQ) Necessity and Concerns subscales (scores out of 25), 8-Item Morisky Medication Adherence Scale (MMAS-8, score out of 8) and self-reported prescription fill rate.

Results: Of 53 patients screened, 20 (37.7\%) were recruited and 7 (35\%) were lost to follow-up at 1 month. The intervention took 25 minutes per patient on average. Intervention group patients scored significantly higher on the BMQ-Necessity subscale compared to controls (24 vs 17.5 ; $\mathrm{p}<0.001)$. No significant difference was found in BMQ-Concerns scores ( 11 vs $15 ; \mathrm{p}=0.102)$; MMAS-8 scores ( 8 vs $8 ; \mathrm{p}=0.430$ ); and prescription fill rates (100\% vs $100 \%)$.

Conclusions: The study recruitment rate is comparable to larger, randomized adherence trials with similar eligibility criteria. Lack of dedicated, funded research staff limited the stringency of follow-up, contributing to the high attrition rate. A larger study is feasible but will require additional resources. The intervention feasibility is highly dependent on pharmacist patient load. Pharmacist discharge counseling and telephone follow-up may improve patients' beliefs about the necessity of their medications.

\section{Evaluation of Melatonin Use for the Management of Insomnia in Elderly Inpatients in a Community Hospital}

Lee M, Ghazi L

North York General Hospital, Toronto, ON

Background: Melatonin was added to the drug formulary at North York General Hospital (NYGH), to provide a safer alternative to benzodiazepines and non-benzodiazepine receptor agonists for the treatment of insomnia, when the latter two classes of drugs are discouraged especially in older adults. Order sets were subsequently modified to replace benzodiazepines with melatonin.

Objectives: To evaluate the prescribing pattern of melatonin among elderly inpatients at NYGH, and to examine the effectiveness and safety of melatonin when used for treating insomnia in this population after the implementation of the revised order sets.
Methods: We conducted a retrospective chart review of inpatients aged 65 years or older, who had a prescription for melatonin for the management of insomnia during the month of May 2016. For each patient, we collected data on demographics, prescription information, concurrent use of sedatives, and the effectiveness and adverse effects of melatonin reported by clinicians. Patients admitted to the intensive care unit were excluded as melatonin was mainly used for the management of delirium.

Results: Among the 794 patients admitted during the study period, $54(6.8 \%)$ patients had an active order for melatonin, $38(70.4 \%)$ of which were newly started in hospital. Concurrent sedatives use was found in $33(61.1 \%)$ of the individuals prescribed melatonin. Thirty-seven patients received at least one dose of melatonin, with doses ranged between 3 and $15 \mathrm{mg}$. Overall, there was an inconsistency in documentation. Among the 22 patients with adequate documentation, $13(59.1 \%)$ were described to have slept well, $5(22.7 \%)$ had partial effects, and ineffectiveness was documented in 4 patients (18.2\%). One patient experienced a fall after having received both melatonin and haloperidol. Conclusions: In this drug utilization evaluation, melatonin appeared to be effective in the management of insomnia in over half of the elderly inpatients with adequate documentation, and was well-tolerated.

\section{Evaluation of the Standardization of Transfer of Accountability between Pharmacists}

Tsoi VK $K^{1}$, Dewhurst $N F^{1,2}$, Tom $E^{2}$, Chant $C^{1,2}$

${ }^{1}$ Leslie Dan Faculty of Pharmacy, University of Toronto, Toronto, ON

${ }^{2}$ St. Michael's Hospital, Toronto, ON

Background: Transfer of Accountability (TOA) is the process of transferring patient information from one health care provider to another at each transition of care. Evidence supports that TOA improves communication, continuity of care and patient safety. Without an alert system upon patient transfer, the ability of pharmacists to seek out and complete TOA may be hindered.

Description: An institutional corporate target was established to ensure TOA amongst all health disciplines. Although TOA was occurring amongst pharmacists, the extent and consistency was not being captured. A standardized pharmacist TOA policy and workflow was created to ensure consistency in documentation and timeliness of practice. Following policy implementation, an evaluation of pharmacist adherence and response was required.

Action: A forced-function notification system was integrated into a TOA workflow to provide an automated alert for pharmacists when patients transfer between units. A retrospective audit of electronic patient records was performed to evaluate pharmacist compliance with the TOA policy. Random samplings of inpatients were identified over three periods pre- and one period post-policy implementation. Each data sampling period included any patients admitted during a pre-specified three month duration. Amongst audited patients, their location(s) throughout their hospital stay were mapped to determine internal transition points for pharmacist TOA. At each transition point, the computerized pharmacy system was reviewed to determine if TOA documentation occurred.

Evaluation: Prior to implementing a standardized TOA policy, the frequency of TOA documentation by pharmacists at each transition point ranged from $10 / 93(11 \%)$ to $24 / 60(40 \%)$. Four months post-policy implementation, the frequency of TOA documentation at each transition point was $68 / 78(87 \%)$, surpassing the institutional target of $70 \%$.

Implications: Implementing a standardized TOA policy with an automated notification system resulted in consistent pharmacist documentation, and doubling of pharmacist TOA. Sustainability of this practice will be evaluated in a future project. 


\section{Evaluation of the Standardization of Pharmacist Involvement in Discharge Medication Reconciliation}

Chen WX', Tsoi VK' ${ }^{1}$, Dewhurst NF', Tom E', Chant $C^{1,2}$

${ }^{1}$ Leslie Dan Faculty of Pharmacy, University of Toronto, Toronto, ON

${ }^{2}$ St. Michael's Hospital, Toronto, ON

Background: Medication reconciliation (MR) is an important safety initiative that reduces medication errors. While criteria had previously been developed to prioritize higher risk patients for pharmacist admission $\mathrm{MR}$, criteria for discharge $\mathrm{MR}$ were not established. In order to balance pharmacist clinical duties, prioritizing patients for discharge MR was necessary.

Description: After developing and implementing discharge MR criteria, an evaluation of patient prioritization by pharmacists was required.

Action: A survey was distributed to all pharmacists to assess their involvement in discharge MR. Data regarding the percentage of pharmacists completing discharge $\mathrm{MR}$, criteria used to prioritize discharge $\mathrm{MR}$, and sources of MR referral were collected. Results were used to develop standardized criteria for discharge MR. Data from a second survey was used to evaluate pharmacists' response to the standardized criteria, frequency of use, and its effect on their practice.

Evaluation: Responses were received from 30 clinical pharmacists practicing on inpatient units. Most pharmacists, 25/30 (83\%), performed discharge MR. The most frequently used criteria for discharge MR included patients taking "high risk" medications, and patients having many changes made to their medication regimen. Main sources of MR referral were by self-selection, 20/27 (74\%), and by physician referral, 6/27 (22\%). Following implementation of standardized discharge MR criteria, 21/23 (91\%) of pharmacists adopted its use. Most pharmacists, $18 / 22(82 \%)$, prioritized patients who met both criteria and 17/21 (81\%) felt that these criteria helped them better select and prioritize their patients.

Implications: Standardized discharge MR criteria were developed, implemented and adopted by pharmacists. The developed criteria effectively prioritizes patients who are discharged on "high risk" medications or have had many changes to their pre-admission medication regimen.

\section{Nabilone for Prevention of Acute Chemotherapy- Induced Nausea and Vomiting in Children: A Single Centre Retrospective Review}

Polito $S^{1}$, Dupuis $L L^{1,2}$, Sung $L^{2}$, Patel $P^{2}$, Ning $W^{2}$, Khanna $M^{2}$

${ }^{1}$ University of Toronto, Toronto, $O N$

${ }^{2}$ The Hospital for Sick Children, Toronto, ON

Background: Children continue to experience chemotherapy-induced nausea and vomiting (CINV) despite receiving antiemetic medication aimed at its prevention. Guidelines for CINV prevention in children have been developed but are limited by the poor quality of existing evidence to support recommendations. Current guidelines recommend the use of nabilone for children receiving moderately to highly emetogenic chemotherapy who cannot receive dexamethasone. However, little published information exists regarding the safety and efficacy of nabilone in children.

Objectives: To describe the efficacy and safety of nabilone for the prevention of acute chemotherapy-induced vomiting (CIV) in children.

Methods: A retrospective chart review of children $\leq 18$ years who received nabilone for acute CINV prophylaxis between December 1, 2010 and August 1, 2015 was undertaken. One course of nabilone was evaluated per child, the $1^{\text {st }}$ during the study period. The proportion of children who experienced complete acute CIV control was determined. The acute phase was defined as starting with the first chemotherapy dose until 24 hours after administration of the last chemotherapy dose of the block. Complete CIV control was defined as no emesis or rescue therapy during the acute phase.

Results: 47 children (mean age: 10.1 years, range: $1.14-17.65$ years; 32 male) received nabilone for acute CINV prophylaxis, 38 of which received nabilone for the duration of the acute phase. Complete CIV control was observed in 34\% (13/38) of children; 38\% (12/32) received highly emetogenic chemotherapy and 16\% (1/6) received moderately emetogenic chemotherapy. 17 children $(36 \%)$ experienced an adverse event associated with nabilone. Sedation (12\%), dizziness (9\%), and headache $(6 \%)$ were the most commonly reported adverse events. All adverse events resolved upon nabilone discontinuation or dose reduction.

Conclusion: Acute CIV control in children receiving nabilone as a part of their antiemetic regimen was poor. Adverse events associated with nabilone were common but of minor clinical significance.

\section{Validation of Patients' Response to the Hospital- Consumer Assessment of Healthcare Providers and Systems (H-CAHPS) Survey Question: "During Your Hospital Stay, Did You Meet with a Pharmacist?"}

Sidhu $V^{7}$, Bresee L L,3,4, Kemp $K^{5}$, Koshman $S^{6}$, Pereira $T^{7}$, Slobodan ${ }^{8}$, Neilson $S^{9}$

${ }^{1}$ Alberta Health Services, Edmonton Zone, Edmonton, $A B$

${ }^{2}$ Alberta Health Services, Calgary Zone, Calgary, $A B$

${ }^{3}$ Department of Community Health Sciences, Cumming School of

Medicine, University of Calgary, Calgary, $A B$

${ }^{4} O$ 'Brien Institute for Public Health, University of Calgary, Calgary, $A B$

${ }^{5}$ Primary Data Support, Analytics (Data Integration, Measurement and Reporting), Calgary, $A B$

${ }^{6}$ Division of Cardiology, University of Alberta, Edmonton, $A B$

${ }^{7}$ Program Performance and Informatics, Alberta Health Services Pharmacy Services, Edmonton, $A B$

${ }^{8}$ Drug Stewardship, Procurement and Inventory, Alberta Health Services Pharmacy Services, Calgary, $A B$

${ }^{9}$ Program Performance, Alberta Health Services Pharmacy Services, Edmonton, $A B$

Background: Our healthcare organization measures inpatient experience using a modified version of the Hospital-Consumer Assessment of Healthcare Providers and Systems (H-CAHPS) survey.

Objectives: To determine the accuracy of patients' response to the H-CAHPS survey question, "During your hospital stay, did you meet with a pharmacist?" through association with pharmacist documentation in the patient record.

Methods: This study was a retrospective chart review of 391 surveyed patients who were discharged between April 2013 and March 2014 from two urban, acute care, teaching hospitals. In the survey, patients were asked whether they had met a pharmacist during their hospital stay (yes/no). Responses were compared to patient charts (gold standard comparator). Charts were examined to determine whether a pharmacist had seen the patient during the hospital admission by the presence or absence of pharmacist documentation. Sensitivity and specificity were calculated to measure the accuracy of the H-CAHPS survey question.

Results: Among the 391 individuals included, 195 (49.9\%) respondents recalled speaking with a pharmacist during their hospital admission and $71(36.4 \%)$ of these individuals had corresponding pharmacist documentation in their charts. However, 196 (50.1\%) respondents did 
not recall speaking with a pharmacist, yet $73(37.2 \%)$ of these individuals had pharmacist documentation in their charts. The overall sensitivity and specificity of the H-CAHPS survey question were 49.3\% (95\% CI: 40.9-57.8\%) and 49.8\% (95\% CI: 43.4-56.2\%), respectively.

Conclusions: These findings suggest patients' recall of pharmacist interaction, as measured by the H-CAHPS survey question, may be inaccurate and warrants further investigation and possible revision of the pharmacy services questions on the survey.

\section{Preventable Medication Errors: Solid Oral Dosage Forms of Diltiazem}

Nguyen $C^{1,3}$, Liu $M^{1,2}, H_{o} C^{1,2,3}$

${ }^{1}$ Institute for Safe Medication Practices Canada, Toronto, ON

${ }^{2}$ School of Pharmacy, University of Waterloo, Kitchener, ON

${ }^{3}$ Leslie Dan Faculty of Pharmacy, University of Toronto, Toronto, ON

Background: Hypertension is a significant risk factor for cardiovascular diseases such as stroke and heart attack, making blood pressure control an important priority in preventing these events. Diltiazem, a nondihydropyridine calcium channel blocker (non-DHP CCB), is used to control blood pressure as a first or second line agent depending on the indication and the patient, with other Health Canada approved indications including stable angina and coronary spasms. Available in a wide range of formulations, generics and doses, diltiazem, if used incorrectly, may lead to negative consequences including heart block and heart failure, and compromise patient safety.

Description: The objective of this multi-incident analysis was to examine potential contributing factors of medication incidents involving solid oral dosage forms of diltiazem, and provide recommendations with the aim to prevent recurrences and enhance patient and medication safety.

Action: Reports of medication incidents involving solid oral dosage forms of diltiazem from January 2010 to April 2016 were extracted from a national incident reporting database. A total of 184 incidents were subjected to a multi-incident analysis.

Evaluation: The incident reports were analyzed and categorized into 2 main themes - diltiazem-specific and medication-use process. Associated subthemes were identified for each main theme, with (1) different formulations and generics, (2) wide dosing ranges, (3) oral dosage forms, (4) drug interactions and (5) non-DHP CCB role in drug therapy under the theme of diltiazem-specific; and (1) prescribing, (2) prescription order entry and (3) prescription preparation/dispensing under the theme of medication-use process.

Implications: By sharing analysis findings and lessons learned, it is hoped to increase the understanding of the medication errors involving diltiazem, and to encourage active discussion and adoption of measures that can improve medication safety.

\section{A Systematic Review of Antimicrobial Stewardship Interventions in the Emergency Department}

\author{
Black $E^{1}$, Ramsey $T^{1,2}$, Losier $M^{1}$, Wilby $K^{3}$ \\ ${ }^{1}$ College of Pharmacy, Dalhousie University, Halifax, NS \\ ${ }^{2}$ Nova Scotia Health Authority, Halifax, NS \\ ${ }^{3}$ College of Pharmacy, Qatar University, Doha, Qatar
}

Background: Infections are one of the most frequent reasons patients present to the emergency department (ED), often resulting in antimicrobial prescribing. Implementation of antimicrobial stewardship programs in the ED has been recommended to improve antimicrobial utilization in this setting.
Objective(s): The primary objective of this study was to characterize antimicrobial stewardship (AMS) in the ED and to identify interventions that improve patient outcomes and/or reduce consequences of antimicrobial use.

Methods: A systematic review was completed to meet study objectives. Medline, EMBASE, Cumulative Index to Nursing and Allied Health Literature, Scopus, and Web of Science were searched from inception through June 2015. All randomized controlled trials, non-randomized controlled trials, controlled and uncontrolled before-after studies, interrupted time series studies, and repeated measures studies which evaluated AMS interventions and reported on patient outcomes, quality of care, or utilization of antimicrobial agents were included in the review. Studies published in languages other than English were excluded.

Results: Thirty-nine studies met inclusion criteria. Most studies were uncontrolled before and after studies with unclear or high risk of bias. The most frequently reported interventions were patient or provider education and guideline or clinical pathway implementation alone or in combination with other interventions. Only 4 studies reported on prescriber audit and feedback. Mixed findings on impact of interventions were identified. Benefits of AMS interventions often included improvement in delivery of care or a decrease in antimicrobial utilization.

Conclusion(s): Implementation of AMS in the ED has the potential to improve patient care however; the majority of studies evaluating antimicrobial stewardship in the ED lacked rigorous design. In addition, few studies evaluated recommended core components of AMS programs including prescriber audit and feedback and pre-authorization. Further high quality research is needed to identify the exact interventions, or combination of interventions, which will optimize antimicrobial use in this setting.

\section{Development of Standardized Hospital-Wide Inpatient Insulin Order Sets for Implementation in an Academic Tertiary Care Centre}

\author{
Halapy $H^{1,2}$, Nguyen-Tri $I^{4}$, Goguen ${ }^{2,3}$ \\ ${ }^{1}$ Leslie Dan Faculty of Pharmacy, University of Toronto, Toronto, ON \\ ${ }^{2}$ St. Michael's Hospital, Toronto, ON \\ ${ }^{3}$ Division of Endocrinology, Department of Medicine, University of \\ Toronto, Toronto, ON \\ ${ }^{4}$ Division of Endocrinology, Department of Medicine, Université Laval, \\ Quebec City, QC
}

Background: Insulin use in the inpatient setting often occurs in a non-standardized way including sliding scale use. At our institution, this practice was compounded with the existence of multiple non-standardized insulin order sets with unclear and unhelpful names in the hospital's order entry system, ultimately leading to low use of the insulin order sets.

Description: In order to simplify and better align inpatient insulin ordering with the Canadian Diabetes Association practice guidelines, we developed 5 standardized inpatient insulin order sets for commonly occurring clinical situations using Plan-Do-Study-Act (PDSA) cycles.

Action: The working group met several times over a year to plan, write, and revise the insulin order sets using a collaborative-based approach. Order sets were written for the following 5 clinical situations: insulin new start, insulin - intravenous use, insulin - continuous feeds, insulin - patient NPO, and insulin - maintenance of home insulin therapy. The order sets were renamed with functional short names descriptive of the clinical situation of intended use. 
Evaluation: Key stakeholders (endocrinologists and general internists) were surveyed in order to obtain their perspectives on content and format. The order sets were also tested on 2 different groups of residents (endocrine and medicine) to help assess clarity and usability. Residents indicated the order sets were overall useful and easy to use. They suggested changes to the names of the order sets, and multiple clarifications to wording. Staff input changed content which allowed amalgamation and simplification of order set content.

Implications: Our approach to insulin order set writing represents a significant improvement in previous order set creation with resultant order sets being more standardized and simpler to understand and being more consistent with practice guidelines. Implementation in the order entry system will occur after appropriate approvals are sought and hospital-wide education is completed.

\section{Determination of Fosfomycin Susceptibility in Multi-Drug Resistant Enterobacteriaceae spp. and Vancomycin-Resistant Enterococci Urinary Isolates \\ Ou L, Nadeau L \\ Windsor Regional Hospital, Windsor, ON}

Background: Broad-spectrum antibiotics are often used for the treatment of urinary tract infections (UTIs) due to resistant Enterobacteriaceae spp. and enterococci [e.g. extended-spectrum B-Lactamase (ESBL) or AmpC production, and vancomycin-resistant enterococci (VRE)], which can promote selection of resistant organisms and may necessitate venous access. Fosfomycin is an orally administered, single dose antibiotic for the treatment of uncomplicated UTIs. Little is known about its microbiologic activity against urinary isolates in the region. Within our institution, prescribers must request fosfomycin susceptibility testing, as it is not routinely performed.

Objective(s): To explore a cost effective alternative for the treatment of UTIs caused by multi-drug resistant Enterobacteriaceae spp. and VRE organisms that are resistant to usual first line therapies by determining fosfomycin susceptibility rates.

Methods: Urinary isolates were collected prospectively from November 2015 through April 2016 at multiple institutions in the region. Susceptibility testing was completed as per Clinical \& Laboratory Standards Institute and interpreted by zone of inhibition in diameter $(\mathrm{mm})$. Urinary isolates from patients $\geq 18$ years old with isolation of multi-drug resistant Enterobacteriaceae spp. or VRE were included for susceptibility testing. The primary outcome was to determine the susceptibility rates of multi-drug resistant Enterobacteriaceae spp. and VRE urinary isolates to fosfomycin.

Results: A total of 141 urinary isolates were included: 109 positive for ESBL- or AmpC-producing Enterobacteriaceae spp. and 32 positive for VRE. Susceptibility rates of ESBL- and AmpC-producing urinary pathogens were $100 \%, 96 \%, 77 \%, 72 \%, 51 \%$, and $16 \%$ for ertapenem, fosfomycin, nitrofurantoin, gentamicin, TMP/SMX and ciprofloxacin respectively. Susceptibility rates of VRE urinary isolates to fosfomycin, ampicillin, penicillin, nitrofurantoin, and ciprofloxacin were $81 \%, 6 \%$, $3 \%, 0 \%$, and $0 \%$ respectively.

Conclusion: Based on the susceptibility rates at our institution, fosfomycin provides an oral, first-line therapeutic option for the treatment of UTIs in patients with suspected or documented multi-drug resistant uropathogens.

\section{Vancomycin Trough Concentrations and Clinical Outcomes in Non-Deep Seated Infections - A Retrospective Study}

\author{
Wan $M^{1}$, Walker $S A N^{1,23,4^{*}}$, Martin $E^{2}$, Elligsen $M^{1}$, Palmay $L^{1}$, Leis $J A^{3,4,5,6}$ \\ ${ }^{1}$ Department of Pharmacy, Sunnybrook Health Sciences Centre (SHSC), \\ Toronto, ON \\ ${ }^{2}$ Leslie Dan Faculty of Pharmacy, University of Toronto, Toronto, ON \\ ${ }^{3}$ Division of Infectious Diseases, SHSC, Toronto, ON \\ ${ }^{4}$ Sunnybrook Research Institute, SHSC, Toronto, ON \\ ${ }^{5}$ Department of Medicine, SHSC, Toronto, ON \\ ${ }^{6}$ Faculty of Medicine, University of Toronto, Toronto, $O N$ \\ * Senior Author; sequence determines credit approach to authorship
}

Background: Vancomycin guidelines recommend dosing to attain trough concentrations $>10 \mathrm{mg} / \mathrm{L}$ in non-deep seated infections. However, no studies have evaluated a risk of clinical failure or demonstrated "development of bacterial resistance to vancomycin used for non-deep seated infections for $\leq 14$ days; thereby, calling into question the value of these recommendations.

Objective: The primary objective was to evaluate patients with non-deep seated infections treated with vancomycin for $\leq 14$ days to determine whether there were differences in clinical outcome with serum trough concentrations of vancomycin $\leq 10 \mathrm{mg} / \mathrm{L}$ (low trough) versus $>10 \mathrm{mg} / \mathrm{L}$ (high trough). The secondary objective was to identify factors that affected clinical outcome.

Methods: A retrospective chart review of patients who received vancomycin, had at least one steady state trough concentration, and were hospitalized between March 10, 2010 and December 31, 2015 was completed. Demographic and clinical outcomes for patients in the low and high trough groups were compared using appropriate statistical tests ( $\mathrm{t}$-test, Fisher's exact, or Mann-Whitney) and binary logistic regression was completed to identify factors associated with clinical outcome. Statistical significance was defined as $\mathrm{p}<0.05$.

Results: A total of $1579 / 2098$ patients (75\%) on vancomycin were screened for eligibility and 71 patients met inclusion criteria. There was no difference in clinical cure between the low (35/39 [90\%]) and high trough $(24 / 32[75 \%])$ groups $(\mathrm{p}=0.12)$. Patients in the high trough group had a larger change in serum creatinine from baseline $(p=0.0458)$ and incidence of nephrotoxicity $(\mathrm{p}=0.037)$. Vancomycin trough concentration was not associated with clinical outcome $(\mathrm{p}=0.102)$.

Conclusion: The results indicate that there is no difference in clinical outcome based on vancomycin trough concentrations in patients with non-deep seated infections, treated with vancomycin for $\leq 14$ days. Targeting higher troughs may be associated with increased nephrotoxicity with no corresponding benefit in clinical outcome in these patients.

\section{Effect of an Intervention to Decrease Antibiotic Use in Asymptomatic Bacteriuria in an Acute Care Setting}

Peters $N^{1}$, Sulz ${ }^{L 2}$, Dumont $Z^{2}$, Malejczyk $K^{2}$, Wray $K^{2}$, Bell $A^{2}$

${ }^{1}$ Winnipeg Regional Health Authority, Winnipeg, $M B$

${ }^{2}$ Regina Qu'Appelle Health Region, Regina, SK

Background: Interpretation of positive urine cultures and diagnosis of urinary tract infections (UTI) is challenging and confounded by asymptomatic bacteriuria (ASB), resulting in inappropriate antibiotic treatment in patients with no indication to receive therapy. This study was designed to evaluate the effect of an intervention on decreasing ordering of urine culture and sensitivities $(C \& S)$ and antibiotic utilization in hospitalized patients with ASB. 
Objectives: The primary objective was to compare the proportion of antibiotics prescribed in hospitalized patients with ASB pre- and postintervention. Secondary objectives included comparing number of urine C\&S ordered per number of patient days, comparing the number and cost of antibiotic therapy and urine C\&S, and to identify whether specific factors (clinical pharmacy services, urinary catheterization, orders for urine $C \& S$ ) impact the intervention to decrease ordering of urine $C \& S$ and antibiotic prescribing in hospitalized patients with ASB.

Methods: This study was a quality improvement initiative with prospective assessment of all adult patients with positive urine $C \& S$ on medical and surgical units. A study protocol based on CDC surveillance definitions for catheter-associated and non-catheter associated UTI in adults was used for assessment. The intervention used in-service education to nurses and pharmacists and a poster to summarize the key intervention information.

Results: The rate of treatment of ASB decreased from 87.5\% (14/16 patients) pre-intervention to $43.8 \%$ (7/16 patients) post-intervention $(\mathrm{p}=0.009)$. The number of urine C\&S ordered per 100 patient days decreased from a rate of 4.97 pre-intervention to 3.76 post-intervention. Overall, catheter use, a physician's order for C\&S, and clinical pharmacy services did not affect the efficacy of the intervention.

Conclusion: This study intervention decreased the rate of treatment of asymptomatic bacteriuria and the rate of urine C\&S ordered. Broader implementation of the intervention to more units and health care providers, including physicians, should be explored.

\section{Aripiprazole Use and the Occurrence of Rhabdomyolysis}

Khan R, Edwards-Lee K

London Health Sciences Centre, London, ON

Background: Aripiprazole is a widely used second generation antipsychotic (SGA) in bipolar disorder, schizophrenia, and as an adjunct in depression. This is a case report of rhabdomyolysis in a patient taking aripiprazole for long-standing depression.

Case Description: An adult female presented with weakness and pain in her arms and legs for the last 2 days with a temperature of $37.8^{\circ} \mathrm{C}$, heart rate of $89 \mathrm{bpm}$, blood pressure of $127 / 57 \mathrm{mmHg}$, respiratory rate of 18 breaths/min, and an elevated Creatinine Kinase (CK) of 23,400 U/L. She had a long history of depression with trials of various antidepressants that were ineffective. Current regimen included escitalopram $20 \mathrm{mg}$ daily and quetiapine $100 \mathrm{mg}$ daily started 3 years ago, and aripriprazole $5 \mathrm{mg}$ daily started a year ago. Benzotropine $1 \mathrm{mg}$ twice daily was also taken the week before admission for pseudoparkinsonism likely from aripiprazole, and was stopped on admission. Neuroleptic Malignant Syndrome and serotonin syndrome were ruled out. Aripiprazole was held and patient was treated with IV fluids over 3 days. CK decreased to 4,332 U/L and symptoms improved.

Assessment of Causality: The stipulated mechanism for this reaction involves blocking serotonin 2A (5HT2A) receptors in skeletal muscle, inhibiting glucose uptake, and thus increasing CK permeability. The Naranjo score was 7, indicating a probable adverse drug reaction.

Literature Review: There are two case reports of rhabdomyolysis in patients taking aripriprazole have been documented. Initial presentation of these patients was similar to the patient being discussed, and their symptoms improved after aripiprazole discontinuation.
Importance to Practitioners: As pharmacists, it is essential to routinely monitor patients on aripiprazole for adverse effects including potential symptoms of rhabdomyolysis and elevated CK levels not only when initiating aripiprazole, but also during long-term treatment.

\section{Needs Assessment for Antimicrobial Stewardship in a Rehabilitation Hospital: A Retrospective, Descriptive Study}

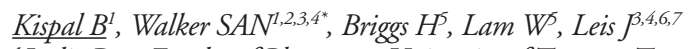

${ }^{1}$ Leslie Dan Faculty of Pharmacy, University of Toronto, Toronto, ON ${ }^{2}$ Department of Pharmacy, Sunnybrook Health Sciences Centre (SHSC), Toronto, $O N$

${ }^{3}$ Division of Infectious Diseases, SHSC, Toronto, ON

${ }^{4}$ Sunnybrook Research Institute, SHSC, Toronto, ON

${ }^{5}$ St. John's Rehabilitation Site, SHSC, Toronto, ON

${ }^{6}$ Department of Medicine, SHSC, Toronto, ON

${ }^{7}$ Faculty of Medicine, University of Toronto, Toronto, ON

Underlined Author: Pharmacy Student working under supervision of Sandra Walker at time of study (Presenter)

* Senior Author; sequence determines credit approach to authorship

Background: Published antimicrobial stewardship (AS) initiatives have focussed on acute care hospitals. AS may be important in rehabilitation hospitals to reduce unnecessary antibiotic use in patients at risk for infection due to their rehabilitation diagnosis (e.g. stroke, burns, trauma, orthopedic surgery) and prolonged hospital stay.

Objective(s): To benchmark antibiotic use and identify potential targets for future AS interventions at a rehabilitation hospital.

Methods: A computerized database retrospective study was conducted at St. John's Rehab Hospital (SJR), affiliated with Sunnybrook Health Sciences Center, Toronto, Ontario. Antibiotic use and microbiology data for all hospitalized patients between July 1, 2015 and June 30, 2016 who were prescribed one or more antibiotics were evaluated. The primary benchmark metrics were days of antibiotic therapy per 1000 patient days, frequency of prolonged antibiotic therapy, identification of most common antibiotics prescribed, and number of cultures sent and processed by microbiology.

Results: During the study period, 980 antibiotic courses were prescribed in 705/2483 patients (28\%; 95\%CI:27-30\%), with 17/705 of these patients (2\%; 95\%CI:1-4\%) admitted on antibiotics; and 447 cultures processed by microbiology. The mean days of antibiotic therapy per 1000 patient days was $138 \pm 17$, with a median duration of therapy of 6 days (IQR:4-8), where 41\% (401/980; 95\%CI:38-44\%) of antibiotics were prescribed greater than 7 days. Fluoroquinolones (27\%; 261/980), cephalosporins $(26 \% ; 256 / 980)$, and penicillins $(17 \% ; 167 / 980)$ were most frequently prescribed. The most common source sent to microbiology for processing was urine (62\%; 279/447;95\%CI:58-67\%), and Escherichia coli was the most common urinary bacteria cultured (60\%; 168/279;95\%CI:54-66\%). Few antibiotic courses were deescalated from intravenous to oral (10\%, 10/87;95\%CI:4-17\%).

Conclusions: Rehabilitation hospitals may benefit from AS initiatives that evaluate appropriate antibiotic duration, de-escalation opportunities, evaluation of all patients prescribed fluoroquinolones, cephalosporins, and penicillins, assessment of urine samples ordered, drawn and processed, and improved empiric prescribing based on a site-specific antibiogram. 


\section{Effects of Reducing the Urine Alkalinisation Threshold Associated with High-Dose Methotrexate Administration}

Drost S, Wentzell J, McLurg D, Sabloff M, Kanji S, Giguere P, Nguyen T The Ottawa Hospital, Ottawa, ON

Background: In hematology-oncology, high-dose methotrexate (HDMTX) is defined as a dose of $\geq 1 \mathrm{~g} / \mathrm{m}^{2}$ and is used in the treatment of acute lymphoblastic leukemia and non-Hodgkin's lymphoma. Urine alkalinisation increases the solubility of methotrexate and reduces the risk of nephrotoxicity. At our institution, patients are electively admitted for HDMTX and receive sodium bicarbonate to alkalinise the urine. Historically, the dose of sodium bicarbonate was titrated to a urine $\mathrm{pH}$ of $\geq 8$ prior to HDMTX. In April 2015 the urine $\mathrm{pH}$ threshold was changed to $\geq 7$ to coincide with other institutions in Canada and practice recommendations.

Objective: The study objective is to determine if a reduction in urine $\mathrm{pH}$ threshold from 8 to 7 results in a change in: (1) HDMTX-related hospital length of stay, (2) HDMTX clearance, and (3) rates of nephrotoxicity. Patient characteristics associated with prolonged HDMTX clearance were identified.

Methods: Data related to patient demographics, urine alkalinisation, methotrexate serum concentration monitoring, length of stay, and renal function were collected retrospectively from electronic records of elective patient admissions for HDMTX from September 1, 2014 to December $18,2015$.

Results: Lowering the urine $\mathrm{pH}$ threshold to 7 from 8 did not affect the hospital length of stay (absolute difference (h) 3.69; 95\% CI -2.83-10.71) or clearance of HDMTX (Ke 0.060 vs. 0.066 , respectively; $\mathrm{p}=0.175$ ). Nephrotoxicity rates were similar between groups ( $15.5 \%$ in the $\geq 7$ group and $10.1 \%$ in the $\geq 8$ group; $p=0.34$ ). The dose of MTX and interacting medications were significantly associated with delayed methotrexate elimination.

Conclusions: There was no significant difference in HDMTX-associated hospital length of stay, HDMTX clearance, or rates of nephrotoxicity between the two different urine $\mathrm{pH}$ thresholds. Interacting medications and dose of MTX were associated with delayed HDMTX elimination.

\section{Measuring Potential Occupational Exposure to Vaporized and Nebulized Finasteride}

Ma N, Perks W, Iazzetta J, Law S, Walker SE

Department of Pharmacy, Sunnybrook Health Sciences Centre, and Leslie Dan Faculty of Pharmacy, University of Toronto, Toronto, ON

Background: The potential for hazardous drug exposure by vapors may vary depending on the formulation, engineering and personal controls utilized and physical properties of the drug. Scant literature exists in this field and no literature was found regarding finasteride.

Objective: The objective was to develop a method to quantify potential occupational exposure by vaporization or nebulization, to hazardous drugs when manufacturing liquid dosage forms and test this method against finasteride suspensions.

Methods: $150 \mathrm{~mL}$ solution of $333 \mu \mathrm{g} / \mathrm{mL}$ finasteride was prepared in $100 \%$ methanol and distilled in a Leibniz condenser. $75 \mathrm{~mL}$ of the distillate was collected and a $200 \mu \mathrm{L}$ distillate sample was tested for finasteride concentrations using a validated reverse-phase stabilityindicating liquid chromatographic (LC) method. To measure potential exposure via nebulization, a mucosal atomization device was used to expel
$2 \mathrm{~mL}$ of $333 \mu \mathrm{g} / \mathrm{mL}$ finasteride suspension upward into an air-sampler (MAS-100-VS®) placed 1 foot above. The MAS-100-VF® was set to sample $1000 \mathrm{~L}$ of air over $10 \mathrm{~min}$. $4 \mathrm{~mL}$ of methanol was used to wash the air-sampling plate and finasteride was quantified in a $200 \mu \mathrm{L}$ sample by LC. The process was repeated with a nebulizing kit. Helium gas was set at a flow of $11 \mathrm{~b} / \mathrm{in}^{2}$ to nebulize $2 \mathrm{~mL}$ of a $333 \mu \mathrm{g} / \mathrm{mL}$ finasteride suspension in water. Air-sampling, plate washing and finasteride concentration analysis was repeated.

Results: LC analysis failed to detect finasteride in the distillate of a methanolic finasteride solution $(0 \mu \mathrm{g} / \mathrm{mL})$. The remaining solution demonstrated conservation of mass, no loss of finasteride. LC analysis of samples collected by the MAS-100-VF® did not detect any finasteride after nebulization with the mucosal atomization device or nebulizing kit.

Conclusion: There was no measurable finasteride when distilled or nebulized. Given the limited risk of respiratory exposure to finasteride in gaseous or nebulized forms, engineering and protective personal measures to prevent respiratory exposure to powders and cutaneous exposure would continue to be recommended.

\section{Prevalence of Penicillin Allergy Verified by Skin Testing in Patients Reporting Allergy to Penicillin \\ Campbell J, Weber E, Tailor L, Walker SE, Shear N \\ Departments of Pharmacy and Medicine, Sunnybrook Health Sciences Centre, and University of Toronto, Toronto, ON}

Background: Although penicillin allergy is reported by up to $10 \%$ of the population, data supporting the true incidence are lacking, as allergy to penicillin is only rarely confirmed. Skin testing is an effective tool to evaluate IgE-mediated allergy to penicillins. At our Drug Safety Clinic (DSC), patients receive skin tests (ST) followed by (if negative) a single oral challenge dose of penicillin $\mathrm{V}$ potassium, to confirm absence of allergy. The DSC standard ST panel consists of penicillin G, minor determinant mixture (MDM, i.e., penilloate, penicilloate), ampicillin, cloxacillin, cefazolin and cefuroxime. Additional beta-lactams are included when indicated by patient history.

Objectives: To determine the prevalence of penicillin allergy in DSC patients reporting a history of penicillin allergy.

Methods: The DSC retrospectively reviewed files for all patients skintested for penicillin allergy from June 12015 to December 312015.

Results: Of the 417 patients reporting a history of penicillin allergy tested during the 7 month period, 11 (2.64\%; 95\%CI: 1.0-4.3\%) had one or more positive skin test results. Based on patient history and skin test results, 3 patients $(0.72 \%$; 95\% CI: $0.0-1.65 \%)$ were advised to avoid all penicillins. All 3 patients tested positive at the penicillin G ST sites, suggesting allergy to the core penicillin molecule; one of these patients also had positive ST at the MDM and ampicillin sites and experienced a systemic reaction. One patient who tested negative to the standard ST panel and tolerated daily oral penicillin $\mathrm{V}$ tested positive to (and experienced a systemic reaction from) ceftriaxone, and later had positive ST to cefoxitin and ceftazidime. Seven patients tested positive to ampicillin only; all require further testing to confirm if they have a selective allergy to aminopenicillins.

Conclusion: Less than $1 \%$ of patients reporting penicillin allergy are allergic to penicillins as a class. 


\section{Medication Adherence Assessment of Patients in a Cardiac Rehabilitation Clinic}

Doucette D

Horizon Health Network, Moncton, NB

Background: Non-adherence to medication is a major public health issue linked to lost work time, wasted healthcare resources, emergency room visits, hospital admission and death. Adherence to medication regimens is uncommonly evaluated with a systematic process or validated tool by frontline clinicians.

Description: Two short validated questionnaires were introduced to assess medication adherence in ambulatory patients with known cardiovascular disease or at high risk of experiencing cardiovascular events.

Action: Medication adherence was assessed on patients enrolled in a 12-week Cardiac Rehabilitation (CR) program. All patients were invited to complete the Adherence Estimator ${ }^{\circledR}$ (AE) tool. Those rated as medium or high risk for adherence problems were eligible for secondary assessment using the Drug Adherence Workup ${ }^{\circledR}$ (DRAW) tool. Individualized interventions were implemented at discretion of the responsible pharmacy team member. All assessments were recorded in the patient electronic health record as part of continuing care.

Evaluation: Over 12 months, 174 CR clinic patients ( 52 females, 122 males) were assessed with these tools. At initial assessment by AE tool, 72 patients (41.4\%) were deemed low risk, 60 (34.5\%) medium risk and $42(24.1 \%)$ high risk for non-adherence. Of patients who screened high or medium risk, secondary assessments (DRAW) identified their most frequent concerns as having too many medications and experiencing side effects. Use of these tools assisted in designing interventions to improve intentional or unintentional behaviours associated with a patient's suboptimal medication-taking. Patient interviews often yielded instances where new drug therapy problems were identified such as complaints of new adverse effects not previously reported by the patient.

Implications: Brief screening with a validated scale found $58.6 \%$ of cardiac rehabilitation patients at high or medium risk for adherence problems with medications. Follow up assessment with a second validated scale in those patients facilitated development of individualized plans to target causes of non-adherence.

\section{Target Dose Achievement of Evidence-Based Medications in Patients with Heart Failure with Reduced Ejection Fraction Attending a Heart Failure Clinic}

Chen $J^{1}$, Galenza $C^{1}$, Ezekowitz F $^{2,3}$, McAlister $F^{2,4}$, Rafuse $K^{5}$, Sande $A^{6}$, Koshman $S^{3}$

${ }^{1}$ Pharmacy Services, Alberta Health Services, Edmonton, $A B$

${ }^{2}$ Canadian VIGOUR Centre, University of Alberta, Edmonton, $A B$

${ }^{3}$ Division of Cardiology, Faculty of Medicine and Dentistry, University of Alberta, Edmonton, $A B$

${ }^{4}$ Division of General Internal Medicine, Faculty of Medicine and

Dentistry, University of Alberta, Edmonton, $A B$

${ }^{5}$ Faculty of Pharmacy and Pharmaceutical Sciences, University of Alberta, Edmonton, $A B$

${ }^{6}$ Heart Function Clinic, Mazankowski Alberta Heart Institute, Alberta Health Services, Edmonton, $A B$

Background: Guidelines recommend both angiotensinconverting enzyme inhibitors (ACEi) or angiotensin receptor blockers (ARB) and betablockers at evidencebased target doses (EBTD) for patients with heart failure $(\mathrm{HF})$ with reduced ejection fraction. Despite utilization of these medications in practice, doses used are often lower than recommended.
Objective(s): The objective of the study was to determine the achievement of EBTD of both ACEi/ARB and beta-blockers within 6 months of entering a HF clinic.

Methods: A retrospective chart review was conducted on consecutive adult patients entering a tertiary HF clinic from October 2012 to February 2015 with a left ventricular ejection fraction (LVEF) $\leq 45 \%$. Exclusion criteria were $<2$ encounters in 12 months, at EBTD of both an ACEi/ARB and beta-blocker at clinic entry, and being deemed ineligible for either medication at baseline. Target dose was that listed in the Canadian Cardiovascular Society HF guidelines.

Results: Of the 359 records screened, 223 (62\%) patients were included (median age 67 years, 77\% male, median LVEF 27\%). Common reasons for exclusion were $\mathrm{LVEF}>45 \%(\mathrm{n}=85)$ and being at EBTD of both an ACEi/ARB and beta-blocker at clinic entry $(n=21)$. Within 6 months, $11 \%$ achieved both ACEi/ARB and beta-blocker EBTD, 54\% ACEi/ARB EBTD, and 22\% beta-blocker EBTD. In those not reaching EBTD, $85 \%$ and $69 \%$ had a documented reason for the ACEi/ARB and beta-blocker, respectively. Hypotension was the most common reason for not achieving EBTD (60\% for ACEi/ARB and 36\% for beta-blockers).

Conclusion(s): Target dose achievement of both ACEi/ARB and beta-blockers within 6 months of entering a tertiary HF clinic was low. With the majority of patients having documented reasons, this may reflect the reality of clinical practice. However, there remained a proportion of patients with suboptimal up-titration, especially of betablockers, indicating opportunities for improvement.

\section{Keeping Mom and Baby Healthy - An Immunization Pilot Project}

Foster $K^{1}$, MacInnis $M^{1,2}$, Isenor $J^{1,2,3}$, Bowles $S^{2,3,4}$, Yazbeck $S^{1}$, Mengual-Fanning $C^{1}$, Cashen $N^{1}$, Cahill $S^{1}$, Macleod $L^{1}$, Slayter $K^{1,2,3}$ ${ }^{1}$ IWK Health Centre, Halifax, NS

${ }^{2}$ Dalhousie University, Halifax, NS

${ }^{3}$ Canadian Center for Vaccinology, Halifax, NS

${ }^{4}$ Nova Scotia Health Authority, Halifax, NS

Background: Vaccinating pregnant women against influenza and pertussis has been shown to protect the pregnant woman, the fetus in-utero and the newborn, however, immunization rates in pregnancy remain low. Our outpatient Perinatal Centre has identified the need to improve immunization rates, however current staffing levels are not able to facilitate this. Patients are therefore referred to their family physician or community pharmacists for immunizations. The literature however, has shown that immunization coverage is improved when the vaccine is provided at the time of recommendation, as opposed to when a person is referred to another provider.

Description: Pharmacists in our province have been permitted to provide immunizations since 2013. A pharmacist with certification to administer vaccines was integrated into the Perinatal Centre to screen clinic attendees for required immunizations, prescribe and to administer vaccines when appropriate.

Action: The pharmacist spent 7 days in the Perinatal Centre over a 1 month period. Nurses and physicians were educated regarding the recommendations for vaccinations in pregnancy. A "Vaccinations for Pregnant Women" patient pamphlet and a "Perinatal Care Immunization Orders" form were created. Also, our institution's immunization policy was updated to include pharmacists.

Evaluation: The pharmacist assessed patients, provided counseling and prescribed and administered 81 vaccinations to pregnant women over the 7 day trial period. While onsite, the pharmacist was also able to answer drug information questions, identify and resolve any drug therapy 
problems and provide medication reviews to other pregnant patients in the Perinatal Centre.

Implications: As a result of the positive feedback from the pilot, a pharmacy consult service is under development for the Perinatal Centre. Clinical pharmacists will be able to be consulted to see high risk outpatients, provide immunizations, provide medication reviews, or provide education to patients and team members on the safety of medications in pregnancy and breastfeeding.

\section{Identifying Care Gaps in the Electronic Discharge Medication Reconciliation Process at an Acute Care Facility}

MacDonald K, Cusack M, Rinco K, Liang R

Queen Elizabeth Hospital, Charlottetown, PE

Background: Studies have shown that many discharged patients experience adverse events, most are medication-related. Accreditation Canada has made medication reconciliation a priority to improve patient safety. The study location is one of few Canadian hospitals to have an electronic discharge process in place. A discharge report has been developed to provide pertinent information to the patient at discharge, including a final medication list to be shared with community pharmacy at the discretion of the patient.

Objective(s): Identify the care gaps related to the discharge medication reconciliation portion of the electronic discharge process at the study site on four nursing units offering medical and surgical services.

Methods: Data for the 8-week prospective study was collected using a Discharge Evaluation Checklist and a Hospital to Community Pharmacy Feedback Form. All inpatients, 65 years of age and older with a length of stay of greater than 4 days and discharged on greater than 5 medications from 4 inpatient nursing units at the site were eligible to participate in this study.

Results: During the study period, data was collected for 72 patients. At least one change in medication regimen occurred in $96 \%$ of these discharges. During follow-up with community pharmacies, $74 \%$ of patients presented to community pharmacy on the day of discharge. Twelve out of 72 discharge reports were received by community pharmacy (16.6\%). Fifty-four patients were discharged home, 11 to long-term care facilities and 7 to community care facilities. Of these patients, $7(13 \%), 1(<10 \%)$ and $4(57 \%)$ provided discharge reports to community pharmacy, respectively.

Conclusion: Based on this study, the largest care gap in the discharge medication reconciliation process at the study site is the failure of the discharge reports to reach community pharmacies.

\section{Stability of a Simple Finasteride $0.33 \mathrm{mg} / \mathrm{mL}$ Suspension Using Tablets in Water and an Oral Mix Vehicle}

Perks W, Law S, Iazzetta J, Ma N, Walker SE Department of Pharmacy, Sunnybrook Health Sciences Centre, and Leslie Dan Faculty of Pharmacy, University of Toronto, Toronto, ON

Background: The stability and formulation of finasteride in suspension vehicles have not been previously reported.

Objective: To evaluate the stability of finasteride $0.33 \mathrm{mg} / \mathrm{mL}$ suspensions prepared in Oral Mix (OM) or Oral Mix SF (SF) or water and stored in amber polyethylene terephthalate (PET) plastic bottles and finasteride $0.33 \mathrm{mg} / \mathrm{mL}$ suspension prepared water and stored in Polypropylene (PP) amber oral plastic syringes over 91 days.
Methods: Six suspensions of finasteride $50 \mathrm{mg} / 150 \mathrm{~mL}(0.33 \mathrm{mg} / \mathrm{mL})$ were prepared from finasteride powder in SF or whole uncrushed finasteride tablets mixed in OM, SF or water in PET bottles. As well, six finasteride $5 \mathrm{mg} / 15 \mathrm{~mL}$ suspensions $(0.33 \mathrm{mg} / \mathrm{mL})$ were prepared from a whole uncrushed finasteride $5 \mathrm{mg}$ tablet mixed with $15 \mathrm{~mL}$ of water in a $20 \mathrm{~mL}$ PP syringe. Half of the samples were stored at $23^{\circ} \mathrm{C}$ and half were stored at $4^{\circ} \mathrm{C}$. On study days $0,1,3,7,14,28,38,49,63,77$ and 91 the finasteride concentration was determined using a validated reverse-phase stability-indicating liquid chromatographic method.

Results: Finasteride concentrations were measured accurate and reproducibly. The finasteride $0.33 \mathrm{mg} / \mathrm{mL}$ in PET bottles in OM, SF or water and in oral syringes in water remained within $5 \%$ of the initial concentration throughout the 91-day study duration. Based on the fastest degradation rate with $95 \%$ confidence, all suspensions regardless of temperature, container or suspending liquid had no less than $94 \%$ remaining on day 91 .

Conclusion: Finasteride $0.33 \mathrm{mg} / \mathrm{mL}$ suspensions are stable in $\mathrm{OM}, \mathrm{SF}$ and water in PET bottles and in PP oral syringes in water, at $23^{\circ} \mathrm{C}$ and $4^{\circ} \mathrm{C}$ for 91 days. The suspension prepared using finasteride powder in $\mathrm{SF}$ is the most pharmaceutically elegant due to the lack of tablet excipients, but the suspension using water in syringes for single doses can be prepared quickly and easily.

\section{Establishing an Environmental Monitoring Program for Viable Airborne Particles in Pharmacy Sterile Rooms}

Hooper C, Findlater C, Carating H, Charbonneau F, Perks W, Iazzetta J, Lye M, Mascioli M, Noce F, Nedzka-Rajwans I, Lacsamana J, Panakkal S, Walker SE

Department of Pharmacy, Sunnybrook Health Sciences Centre, and Leslie Dan Faculty of Pharmacy, University of Toronto, Toronto, ON

Background: USP 797 and NAPRA have set recognized standards for the compounding of sterile pharmaceutical preparations. The standard requires that air and surfaces in sterile compounding areas undergo regular monitoring to ensure the environment remains suitable for compounding. Our objective was to develop and implement an environmental monitoring program to measure viable airborne particles in pharmacy sterile rooms.

Action: A sampling plan was developed to sample various sites within each of the 5 sterile compounding areas (CBA). Each CBA and 11 sterile hoods (Primary Engineering Controls - PEC) were sampled using a volumetric air sampler in static and active operating conditions. Each sample was collected in duplicate, sampling $1000 \mathrm{~L}$ of air onto Tryptic Soy Agar media. Plates were incubated at $30-35^{\circ} \mathrm{C}$ for 72 hours. Any growth was recorded as colony forming units (CFUs)/m3 and sent for microbial identification. CFU action levels were adopted from USP 797/NAPRA requirements. Areas that had fewer CFUs than the action level for its ISO classification were considered to have passed.

Evaluation: 117 samples at 30 sites in 5 sterile rooms were obtained. Of 11 PEC, none produced CFUs. Of the 14 sites in the sterile rooms, all produced $<10 \mathrm{CFUs}$ (median $1 \mathrm{CFU} / \mathrm{m}^{3}$, range $0-6 \mathrm{CFU} / \mathrm{m}^{3}$ ). Of the 5 sites in the anterooms, all produced $<100 \mathrm{CFUs}$ (median $0 \mathrm{CFU} / \mathrm{m}^{3}$, range $0-12 \mathrm{CFU} / \mathrm{m}^{3}$ ). The bacteria identified in the air were coagulasenegative staphylococci, micrococcus, aerococcus, and aerobic sporeforming bacilli.

Implications: All sites were below the action level for viable airborne particles based on ISO Classification. Blinds on exterior windows consistently produced growth. Blinds were removed and subsequent testing demonstrated improvement. The USP 797/NAPRA requirement 
for a monthly environmental monitoring program makes this in-house program cost effective. Program expansion to include non-viable particulate and surface sampling is required to achieve compliance with USP 797/NAPRA environmental surveillance standards.

\section{Stability of 0.2 and $10 \mathrm{mg} / \mathrm{mL}$ Hydromorphone Solutions in CADD $\otimes$ Reservoirs, PVC and Ethylene/Propylene Co-Polymer (PAB囚) Bags at Room Temperature $\left(23^{\circ} \mathrm{C}\right)$}

\section{Law S, Perks W, Iazzetta J, Walker SE}

Department of Pharmacy, Sunnybrook Health Sciences Centre, and Leslie Dan Faculty of Pharmacy, University of Toronto, Toronto, ON

Background: Facilities without securely lockable refrigerators may store compounded narcotic infusions in a locked cabinet at room temperature which may result in reduced stability and potential water loss during prolonged storage.

Objective: To evaluate the stability of hydromorphone $0.2 \mathrm{mg} / \mathrm{mL}$ and $10 \mathrm{mg} / \mathrm{mL}$ solutions in $0.9 \%$ sodium chloride (NS) and water loss during storage over 90 days at room temperature in CADD reservoirs, PVC bags and $\mathrm{PAB} 囚$ bags.

Methods: On study day $0,100 \mathrm{~mL}$ solutions of $0.2 \mathrm{mg} / \mathrm{mL}$ and $10 \mathrm{mg} / \mathrm{mL}$ concentrations of hydromorphone were prepared in NS. Four units of each solution were stored at room temperature. Concentration, physical inspection and bag weights were completed on study days 0,1 , $3,7,14,24,38,56,76$, and 90 . Hydromorphone concentrations were determined by a validated stability-indicating liquid chromatographic method with UV detection. Chemical stability was based on the intersection of the lower limit of the $95 \%$ confidence interval of the observed degradation rate and the time to achieve $90 \%$ of the initial concentration.

Results: The analytical method measured hydromorphone concentrations specifically, accurately (deviations averaged 2.52\%) and reproducibly (replicate error of study samples averaged $0.71 \%(\mathrm{CV}(\%))$ ). During the study, water loss was apparent in PVC and CADD reservoirs, increasing concentrations by 8 and $6 \%$, respectively. When corrected for water loss, the average concentration varied by less than $0.55 \%$ over the 90-day period and solutions retained more than $97 \%$ of the initial concentration, with $95 \%$ confidence. Chemical stability exceeded 90 days for all containers.

Conclusions: We conclude that hydromorphone concentrations of $0.2 \mathrm{mg} / \mathrm{mL}$ and $10 \mathrm{mg} / \mathrm{mL}$ in PVC bags, CADD reservoirs and PAB ${ }^{\circledR}$ containers are physically and chemically stable for at least 90 days at room temperature $\left(23^{\circ} \mathrm{C}\right)$. Water loss, resulting in rising hydromorphone concentrations, were apparent in PVC bags and CADD reservoirs but not $\mathrm{PAB} \AA$ containers.

\section{Stability of $0.05 \mathrm{mg} / \mathrm{mL}$ Sufentanil Solutions in CADD $\otimes$ Reservoirs, PVC Containers, Ethylene/Propylene Co-Polymer (PAB $®)$ Bags and Syringes at Room Temperature $\left(23^{\circ} \mathrm{C}\right)$}

\section{Law S, Perks W, Iazzetta J, Walker SE}

Department of Pharmacy, Sunnybrook Health Sciences Centre, and Leslie Dan Faculty of Pharmacy, University of Toronto, Toronto, ON

Background: Publications have demonstrated the stability of sufentanil solutions for up to 70 days. We sought to evaluate the interaction of chemical stability and water loss on the actual concentration in several containers.
Objective: To evaluate the stability of sufentanil $0.05 \mathrm{mg} / \mathrm{mL}$ solutions and water loss over 90 days at room temperature in CADD reservoirs, PVC bags, PAB® bags and polypropylene syringes.

Methods: On study day $0,50 \mathrm{~mL}$ solutions of $0.05 \mathrm{mg} / \mathrm{mL}$ concentrations of sufentanil were prepared. Four units of each container were stored at room temperature and 4 additional CADD reservoirs were stored at 4C. Concentration, physical inspection and bag weights were completed on days $0,1,4,7,14,21,35,56,70$, and 90 . Sufentanil concentrations were determined by a validated stability-indicating liquid chromatographic method with UV detection. Chemical stability was based on the intersection of the lower limit of the $95 \%$ confidence interval of the observed degradation rate and the time to achieve $90 \%$ of the initial concentration after correction for water loss.

Results: The analytical method measured sufentanil concentrations specifically, accurately (deviations averaged $2.44 \%$ ) and reproducibly (replicate error of $1.0 \%(\mathrm{CV} \%)$. During the study, water loss was apparent in PVC and CADD reservoirs increasing concentrations by 18 and $15 \%$, respectively at room temperature. When corrected for water loss, the average concentration varied by less than $2.53 \%$ over the 90-day period and solutions retained a concentration within $6.45 \%$ of the initial, with $95 \%$ confidence. Chemical stability exceeded 90 days for all containers.

Conclusions: We conclude that sufentanil concentrations of $0.050 \mathrm{mg} / \mathrm{mL}$ are physically and chemically stable for at least 90 days room temperature $\left(23^{\circ} \mathrm{C}\right)$ in PVC bags, CADD reservoirs, $\mathrm{PAB}$ containers or polypropylene syringes and at $4 \mathrm{C}$ in $\mathrm{CADD}$ reservoirs. Water loss may limit the beyond-use-date on PVC bags and CADD reservoirs during room temperature storage.

\section{Stop, Drop, and Shake: Developing a Finasteride Oral Liquid Preparation in Distilled Water or Oral Mix Vehicle Using Whole Uncrushed Tablets}

Ma N, Perks W, Law S, Iazzetta J, Walker SE

Department of Pharmacy, Sunnybrook Health Sciences Centre, and Leslie Dan Faculty of Pharmacy, University of Toronto, Toronto, ON

Background: There are no finasteride oral liquid preparations commercially available in Canada. Dysphagic patients require drugs be administered as a liquid preparations requiring extemporaneous compounding. Crushing tablets during the compounding process, potentially dispersing particles into the air, increases the risk of occupational exposure. This is particularly dangerous when compounding hazardous drugs.

Objective: To develop a $0.333 \mathrm{mg} / \mathrm{mL}$ finasteride suspension in Oral Mix (OM) that minimizes exposure to finasteride particulates during preparation.

Methods: Disintegration of 9 generic brands of finasteride tablets (Sandoz, Apotex, Teva, Pharmascience, Mint, Actavis, Jamp, Auro and Accord) was completed. For each brand, 5 finasteride $5 \mathrm{mg}$ tablets were placed in $75 \mathrm{~mL}$ of distilled water in a round bottom flask. Using a VWR Dyla-Dual $\Subset$ stirrer with a 1-inch magnetic stir bar rotating at Speed 1, $12-200 \mu \mathrm{L}$ samples were taken during dissolution. Dissolution was repeated with Sandoz-Finasteride tablets in OM using the same method as above except the stirrer was set to speed 5 and samples were taken every $5 \mathrm{~min}$ for $60 \mathrm{~min}$. A third dissolution test was completed with all generic manufacturers. Ten finasteride $5 \mathrm{mg}$ tablets in a $175 \mathrm{~mL}$ amber polyethylene terephthalate (PET) plastic bottle containing $150 \mathrm{~mL} \mathrm{OM}$ were shaken at 180 shakes $/ \mathrm{min}$ for $30 \mathrm{sec}$ every $5 \mathrm{~min}$ for $60 \mathrm{~min}$. Samples were taken at 41,51 and $61 \mathrm{~min}$. Finasteride concentrations were 
quantified using a validated reverse-phase stability-indicating liquid chromatographic method.

Results: All generic formulations achieved no less than $90 \%$ of expected concentration $(0.333 \mathrm{mg} / \mathrm{mL})$ in distilled water within $4 \mathrm{~min}$ when stirred, and in OM within 60min when shaken manually. Sandoz-Finasteride dissolution in OM achieved no less than $90 \%$ of expected concentration $(0.333 \mathrm{mg} / \mathrm{mL})$ in $52 \mathrm{~min}$ while stirred.

Conclusion: Finasteride oral liquid preparations that deliver the expected final concentrations can be compounded simply by dropping whole tablets of any generic formulation into either distilled water or OM, and shaking. Crushing is not necessary.

\section{A Retrospective Audit of Medication Prescribing Practices: A Quality Improvement Initiative \\ Cicinelli $E^{1}$, Liu $R^{1}$, Saifi $T^{1}$, Lachere F', Apio F', Cheng $D^{1}$ \\ ${ }^{1}$ Leslie Dan Faculty of Pharmacy, University of Toronto, Toronto, ON \\ ${ }^{2}$ St. Mary's Hospital Lacor, Gulu, Uganda}

Background: Adverse drug events due to medication errors can occur at the prescribing, dispensing, and administration levels of drug use and are considered preventable. At the prescribing stage, medication errors can occur due to illegible handwriting, incomplete orders, and dangerous abbreviations. Patient and medication safety initiatives in low-resource settings may face more barriers than in high-income countries. We aim to describe the prescribing practices (adherence to institutional and national practice guidelines, and missing components of orders) in a large acute care institution in Uganda.

Description: Retrospective reviews were carried out to determine the presence of all required components of a medication order and adherence to institutional and national clinical guidelines were assessed. An order was confirmed to have followed guidelines if it was legible, written using full generic names, and included all components of an order (i.e. drug, strength, dose, frequency, and duration of therapy).

Action: A data collection tool was created to record details about components of the orders such as the diagnosis, indication, and adherence to available guidelines. Data collection took place over 1 week and was completed by 3 pharmacy team members.

Evaluation: Overall, 282 orders were assessed. Of these, 108 (38\%) and $114(41 \%)$ orders were adherent to institutional and national practice guidelines, respectively. The most common missing components of an order were duration of therapy $(81 \%)$, followed by indication $(34 \%)$, and frequency $(7 \%)$.

Implications: This preliminary audit is part of a larger, interdisciplinary initiative led by the hospital's pharmacy department to improve pharmaceutical care and patient outcomes at a large acute care hospital in Uganda. The data collected from this study will inform the development of systems and interventions (e.g. implementation of antimicrobial stewardship principles, pre-printed order sets, etc.) to improve prescribing practices.

\section{Near-Peer Facilitation in Delivering Pharmacy Practice Skills for Pharmacy Students}

Mak J, Lee A

Leslie Dan Faculty of Pharmacy, University of Toronto, Toronto, ON

Background: Near-peer teaching provides opportunities for mutual growth for all peer parties. We examined the perceived impact of near-peer facilitation in delivering pharmacy practice skills.
Description: This two year study gathered perceptions from first year pharmacy students on the impact of third year pharmacy student involvement in the facilitation of a first year pharmacy practice course. Third year pharmacy students received training on facilitation through their coursework.

Action: In 2015, third year students facilitated a first year pharmacy practice lab course on the topic of MedsCheck. For 2016, third year students were provided the opportunity to facilitated a MedsCheck and a Topical Medications lab in the same pharmacy practice course. A post-lab online survey was administered to first year students using 5-point Likert scales and open-ended questions to gather their perceptions of third year students' abilities to put students at ease and provide useful feedback.

Evaluation: Fifty-four first year students responded to the 2015 survey, and 48 students responded to the 2016 survey. For the 2015 cohort, $63 \%$ agreed ( 4 of 5) or strongly agreed ( 5 of 5 ) that third year student facilitators made them feel at ease in the lab, and the 2016 cohort had a similar result of 51\% (MedsChecks lab) and 63\% (Topicals lab) agreeing or strongly agreeing with the same statement. In $2015,73 \%$ of respondents and in $2016,75 \%$ of respondents agreed or strongly agreed that third year student feedback improved their medication history gathering skills. Students praised the high quality and variety of third year student feedback, while citing standardized feedback as an area for improvement.

Implications: First year pharmacy students perceived third year pharmacy student facilitators as having a positive impact on student learning for pharmacy practice skills, with high potential for applications in future pharmacy education.

\section{Ketamine for the Treatment of Acute Pain in the Pre-Hospital and Emergency Department Setting: A Systematic Review}

\author{
LeBras $M H^{1}$, Stacey $D T^{2}$, Zed P \\ ${ }^{1}$ RxFiles Academic Detailing Program, Saskatchewan City Hospital, \\ Saskatoon, SK \\ ${ }^{2}$ Canadian Forces - Department of National Defence, Borden, ON \\ ${ }^{3}$ Faculty of Pharmaceutical Sciences, University of British Columbia, \\ Vancouver, $B C$
}

Background: Ketamine has been utilized to manage acute pain. Observational studies have demonstrated pain relief with ketamine as monotherapy, in combination with opioids, and after opioids have failed. Objective: To compare the efficacy and safety of ketamine monotherapy, or as an adjuvant to opioids, for the treatment of acute pain in the pre-hospital or ED setting.

Methods: MEDLINE, EMBASE, CENTRAL, Google and ClinicalTrials.gov were searched from inception to October 2016 using the search terms: ketamine; acute pain; pain management; analgesia; emergency service, hospital; emergency department; pre-hospital; out-of-hospital. Randomized controlled trials (RCTs) investigating ketamine compared to placebo or active comparators in adult or pediatric patients with acute pain in the pre-hospital or ED setting were included. The quality of included trials was evaluated using The Cochrane Collaboration's risk of bias tool.

Results: Eight RCTs enrolling a total of 991 patients were included. The majority of trials assessed ketamine monotherapy; however, 2 trials assessed combination ketamine and morphine compared to morphine monotherapy. The average ketamine dose was $0.2-0.3 \mathrm{mg} / \mathrm{kg}$ given as an intermittent intravenous infusion over 5-10 minutes. The majority of 
trials demonstrated no consistent, clinically significant difference in pain response (pain score changes, complete pain resolution, need for rescue analgesia) or satisfaction with ketamine monotherapy or in combination with morphine compared to morphine monotherapy. Dizziness and disorientation were consistently greater with ketamine. Benzodiazepines were not necessary for prevention or treatment of emergence reactions. All trials had methodological limitations. Determining ketamine's overall effect was limited due to the multiple pain score tools utilized and lack of systematic adverse event assessment.

Conclusions: Available data suggests no consistent difference in efficacy nor safety between ketamine monotherapy or as an adjunct to morphine compared to morphine alone. Additional trials will help understand the effectiveness, safety, and use of ketamine for acute pain.

\section{How Do Patient, Pharmacist and Interprofessional Stakeholder Perspectives on Clinical Pharmacy Key Performance Indicators Compare across Canada?}

Mourao $D^{1}$,Raymond $C^{2}$,Slobodan ${ }^{3}$, Gorman $S^{4}$, Meade $A^{5}$, Toombs $K^{5}$, Attfield $E^{6}$, Sykelyk $A^{7}$, Newman ${ }^{8}$, Nghiem $C^{9}$, Law $V^{10}$, Saad $M^{9}$, Fernandes $O^{1,9}$

${ }^{1}$ University Health Network, Toronto, ON

${ }^{2}$ Manitoba Centre for Health Policy, University of Manitoba, Winnipeg, $M B$ ${ }^{3}$ Alberta Health Services, Red Deer, AB

${ }^{4}$ Interior Health Authority, Kelowna, BC

${ }^{5}$ Capital District Health Authority, Halifax, NS

${ }^{6}$ Lower Mainland Pharmacy Services, Surrey, BC

${ }^{7}$ Lower Mainland Pharmacy Services, Vancouver, BC

${ }^{8}$ Covenant Health, Edmonton, $A B$

${ }^{9}$ Leslie Dan Faculty of Pharmacy, University of Toronto, Toronto, ON

${ }^{10}$ St. Michael's Hospital, Toronto, ON

Background: The evidence-informed consensus process of developing the national clinical pharmacy key performance indicators (cpKPI) for hospital pharmacists to date has not involved national stakeholder feedback.

Description: To systematically gather national stakeholder feedback on the cpKPI and compare quantitative data among stakeholder subgroups to refine and optimize the cpKPI.

Action: Stakeholders were administered a questionnaire, in person as part of an interview or focus group, which asked participants to rank the cpKPIs.A stakeholder included: (i) a person or leader who regularly interacts with an inpatient hospital pharmacist; (ii) a person involved in the measurement of quality/performance indicators; or (iii) a recipient of direct patient care from an inpatient hospital pharmacist.

Evaluation: Feedback was gathered from 214 stakeholders (79 hospital pharmacists, 92other health professionals or administrators and 43 patients). Overall, of 204 participants who responded to the question, 181 participants $(89 \%)$ agreed or strongly agreed that measuring these cpKPI for hospital pharmacists will be useful in advancing clinical pharmacy practice to improve the quality of patient care. Prioritization of the cpKPI differed among stakeholder subgroups and across provinces. Nationally, drug therapy problems resolved was the highest priority cpKPI for hospital pharmacists, whereas admission and discharge medication reconciliation were the highest priority for non-patients and patients respectively.

For the table that goes with this abstract, please see Abstract Appendix, available at www.cjhp-online.ca/index.php/cjhp/issue/view/119/ show Toc
Implications: Stakeholders felt that measuring these consensus cpKPIs is important, although there is some variation among stakeholder subgroups and provinces as to the most important cpKPI. Provincial differences may reflect variances in pharmacist services delivered or local health care priorities. These perspectives will serve to optimize the consensus cpKPI and prioritize implementation.

\section{Preceptor/Assessor Training Regarding Use of a Standard Assessment Tool for Field-Based Pharmacy Education}

\section{Halapy $H^{1,4}$, Lee $A^{1}$, Spizzirri $D^{2}$, Tolmie $A^{3}$}

${ }^{1}$ Leslie Dan Faculty of Pharmacy, University of Toronto, Toronto, ON

${ }^{2}$ Ontario College of Pharmacists, Toronto, ON

${ }^{3}$ School of Pharmacy, University of Waterloo, Waterloo, ON

${ }^{4}$ Hospital Pharmacy Residency Forum of Ontario, ON

Background: A standard competency-based assessment tool for field-based pharmacy training was implemented in the last year by the provincial schools of pharmacy, residency training sites and provincial licensing body. Assessment tool training could help with standardizing the preceptor/ assessor approach to tool utilization.

Description: A preceptor training program was developed through collaboration with representatives of the 3 training programs and provincial regulatory body. The resultant training program includes a presentation describing the tool features plus a series of case-based discussions to facilitate tool application and grade norming.

Action: A slide deck was developed to introduce the assessment tool, including a description of its key features such as the 5 domains assessed by the tool and the tool's use of a 5 point Likert scale for grading. Five cases were developed which served as a discussion point for applying the tool. The training program was delivered in two formats: 1) a two part workshop version with pre-workshop preparation plus small live breakout groups facilitated by the authors; and 2) an interactive online presentation incorporating a learner case video describing examples for applying the tool in assessment. Feedback regarding the training was sought from preceptors/ assessors completing the program.

Evaluation: Hundreds of preceptors/ assessors have completed the training program and evaluations following training program completion have indicated that the preceptors/ assessors found it helpful. The evaluations indicated that preceptors/ assessors felt more confident and better prepared to utilize the assessment tool. Feedback also indicated the need to refine the cases in order to make them more clear and useful for training. These case revisions have been completed.

Implications: A case-based preceptor/ assessor training program for a recently implemented provincial assessment tool was found to increase preceptor self-reported confidence regarding tool utilization.

\section{Hospital Pharmacists' Skills Development Grid and Job Standards Timeline: Description of Development and Use at a Pediatric Tertiary Care Institution}

Yung $J^{1}$, Nijjar $J^{1}$, Dupuis $L L^{1,2}$, Seto $W^{1,2}$, Chen $L^{2}$, Taylor $T^{2}$, Trope $A^{2}$, Tjon J,2

${ }^{1}$ Leslie Dan Faculty of Pharmacy, University of Toronto, Toronto, ON

${ }^{2}$ Department of Pharmacy, The Hospital for Sick Children, Toronto, ON

Background: Three unique tools used to guide hospital pharmacists' professional development and appraise their performance have been described. Existing tools are insufficient as none provide both a compre- 
hensive outline of hospital pharmacy competencies and a skill development timeline. We sought to produce both a tool to guide hospital pharmacists' professional development and a timeline for competency achievement across all pharmacy practice domains.

Description: The Pharmacists' Skills Development Grid (PSDG) describes the progression from novice through mastery within 8 pharmacy practice domains: administration, distribution, drug information, pharmaceutical care, pharmacokinetics or therapeutic drug monitoring, production, research and projects, and teaching. The Job Standards Timeline (JST) defines the expected skill level of pharmacists in each domain according to length of service.

Action: The PSDG was established in 1998 at a pediatric institution and underwent a third revision in 2012. Both its original development and revisions were accomplished by task forces comprised of pediatric pharmacists, with input from all pharmacists.

Evaluation: Managers and pharmacists have used the PSDG as a tool to guide the development of personal objectives and to facilitate performance appraisal. In 2012, a survey was sent to all pharmacists $(n=36)$ requesting feedback on the revised PSDG. All respondents $(n=12)$ either agreed or strongly agreed that: the PSDG was needed, the timeline was appropriate, and the PSDG and JST were complete and easy to understand. Future steps include prospective evaluation of changes in pharmacist performance to validate the PSDG's utility.

Implications: Compared to similar tools, the PSDG and JST provide a more comprehensive description of competencies specific to hospital pharmacy practice and a timeline for skill development. The PSDG provides guidance to hospital pharmacists when selecting professional development activities and to clinical managers when appraising staff performance. Since it encompasses all hospital pharmacy practice domains, the PSDG and JST are widely applicable.

\section{Aide humanitaire et contribution des pharmaciens : une revue de littérature}

Langlois $H^{1}$, Aussedat $M^{1}$, Bussières $J F^{1,2}$

${ }^{1}$ Département de pharmacie et Unité de recherche en pratique pharmaceutique, CHU Sainte-Justine, Montréal, QC

${ }^{2}$ Faculté de pharmacie, Université de Montréal, Montréal, QC

Contexte : Au sein de l'aide humanitaire, les pharmaciens jouent un rôle primordial dans l'approvisionnement en médicaments, le maintien de la chaîne du froid ou encore dans le choix approprié de pharmacothérapie.

Objectif : L'objectif de cette étude est de présenter une revue de la littérature des articles présentant les rôles et retombées des pharmaciens humanitaires dans les pays en développement.

Méthodes : Une stratégie sur Pubmed et une recherche manuelle ont été effectuées de 1990 à juillet 2016. Les articles présentant les rôles et retombées des pharmaciens humanitaire dans les pays en développement ont été sélectionnés et ceux portant sur les rôles au sein de pays développés ont été exclus. Un profil des rôles et retombées du pharmacien a été établi selon plusieurs variables (auteur principal, année de publication, lieu de la mission, bailleur de fond, objectif(s) de l'étude, durée de la mission, intervenant(s), type(s) d'intervention(s), principaux résultats). Aucune analyse statistique n'a été effectuée.

Résultats : Dix-huit articles ont été inclus et analysés. Parmi les articles identifiés, quatorze décrivent les interventions du pharmacien en mission humanitaire, dix font état d'un impact positif des rôles et retombées du pharmacien et seulement deux exposent un suivi des actions mises en place. Les activités pour lesquelles les pharmaciens sont majoritairement impliqués sont l'enseignement aux professionnels de la santé ou aux patients $(n=9)$, la réorganisation logistique du circuit du médicament $(n=8)$, la rédaction de politiques et procédures $(n=8)$, les soins pharmaceutiques $(n=7)$ et la délivrance de médicaments $(n=7)$.

Conclusion : Il existe très peu de données relatives aux rôles et retombées du pharmacien en mission humanitaire dans les pays en développement. Des expériences publiées, les pharmaciens jouent principalement un rôle dans l'enseignement, la restructuration du circuit du médicament et la sécurisation des approvisionnements en médicaments. Les contributions des pharmaciens en mission humanitaire méritent d'être encouragées.

\section{Evaluation of Medication Reconciliation by Pharmacy Technicians in the Emergency Department}

McMillan K, Howorko J, Abell R

Red Deer Regional Hospital Centre, Red Deer, $A B$

Background: Pharmacy Technicians were added to complete the Best Possible Medication History (BPMH) in the Emergency Department (ED) in January 2014 to facilitate the first step of medication reconciliation. Evaluation of the program has not been formally assessed.

Description: Pharmacy technicians complete BPMHs in the ED 7 days/week from 1245-2100h (1.4 FTE). Six technicians were trained and rotate through this position. Workload data from 2015 was reviewed and satisfaction surveys were completed.

Action: Workload data collated from real time tracking by Pharmacy Technicians included: number of BPMHs completed per shift, time to complete each BPMH, number of medications per BPMH and if the request to generate a BPMH was completed. Separate satisfaction surveys for ED and Pharmacy staff were conducted.

Evaluation: A total of 2099 BPMHs were completed. The average time to completion was 39.3 minutes with an average of 11.6 medications per $\mathrm{BPMH}$. As the number of medications increased, time to complete the $\mathrm{BPMH}$ increased. A BPMH with one medication averaged 11 minutes to complete, while BPMHs with more than 20 medications averaged 59 minutes. Over $140 \mathrm{BPMHs}$ contained more than 20 medications. Eighty-three responses were received from the ED team satisfaction survey. Over $90 \%$ of ED respondents agreed that phone calls and order clarifications were decreased, patient flow improved, and the quality of BPMH improved with technician led BPMHs. All respondents found the addition to the ED team valuable. Fifty-three responses were received from the Pharmacy team survey. Over 95\% of Pharmacy respondents reported the initiative resulted in decreased phone calls from the dispensary, reduced errors, and a more complete BPMH.

Implications: Pharmacy technicians are a cost effective solution for medication reconciliation activities for select patients within the ED. The Technician role in leading medication reconciliation can improve efficiencies and safety in medication management.

\section{Travail de proximité des pharmaciens dans les groupes de médecine de famille : l'impact sur la collaboration et la communication interprofessionnelle}

Sanon P-N, Grenier-Gosselin L, Guénette L Faculté de pharmacie, Université Laval, Centre de recherche du CHU de Québec, Québec, QC

Contexte : Des initiatives pour intégrer des pharmaciens $(\mathrm{Ph})$ dans les groupes de médecine de famille (GMF) ont vu le jour récemment au Québec. Leur arrivée dans ces équipes multidisciplinaires et leur rôle dans le suivi des clientèles est une innovation dont les impacts ont très peu été étudiés. 
Description : Évaluer l'intégration et l'impact des activités d'un pharmacien au sein d'une équipe de soins de première ligne sur la collaboration et la communication interprofessionnelle.

Action : Une étude à devis mixte a été effectuée à l'aide d'entrevues semi-structurées et de questionnaires (Pharmacist-Physician Collaborative Index (PPCI) et Inventaire du climat d'équipe (ICE)) auprès de médecins (Md), pharmaciens et autres professionnels. Une analyse de contenu thématique est en cours pour les entrevues de même que des analyses comparant les différents milieux et les professionnels.

Évaluation : 30 professionnels ont été rencontrés $(6 \mathrm{Ph}, 13 \mathrm{Md}$ et 11 autres). Les résultats préliminaires des entrevues nous indiquent que l'intégration réussie du pharmacien en GMF demande du temps et des efforts de l'organisation, du $\mathrm{Ph}$ et des autres professionnels, notamment au regard de la compréhension des rôles afin de diminuer les appréhensions. Les questionnaires révèlent des différences statistiques au niveau des appréhensions de la collaboration interprofessionnelle par type de professionnels (Score ICE : $\mathrm{ph}=86,17 \mathrm{md}=77,84$ autres=79,64 avec un $\mathrm{p}=<.0001$ ).

Répercussions : Ces résultats permettront de mieux comprendre l'intégration du pharmacien en GMF et les impacts organisationnels que peuvent avoir ces professionnels de la santé dans les équipes interdisciplinaires de première ligne.

\section{Patient Perspectives on Clinical Pharmacy Key Performance Indicators: A Qualitative Study}

Gorman $S^{1}$, Raymond $C^{2}$, Mourao $D^{3}$, Meade $A^{4}$, Toombs $K^{4}$, Poggemoeller $K^{5}$, Sykelyk $A^{6}$, Fernandes $O^{3}$

${ }^{I}$ Interior Health Authority, Kelowna, $B C$

${ }^{2}$ University of Manitoba, Winnipeg, $M B$

${ }^{3}$ University Health Network, Toronto, ON

${ }^{4}$ Nova Scotia Health Authority, Halifax, NS

${ }^{5}$ University of British Columbia, Vancouver, $B C$

${ }^{6}$ Lower Mainland Pharmacy Services, Vancouver, BC

Background: Clinical pharmacy key performance indicators (cpKPI) are measures of hospital pharmacist service quality. Eight cpKPI have been developed to advance practice and improve the quality of patient care. Patient perspectives on cpKPI relative importance and meaning are essential to implement and communicate cpKPI in a patient and family centered manner.

Objectives: To 1) describe patients' perceptions of the relative importance of the cpKPI and their rationale behind this, 2) to identify areas for improved cpKPI description for patient audiences, and to 3) describe patients' perceptions of the cpKPI stakeholder experience.

Methods: This was a prospective, multi-centre, multi-province qualitative descriptive study. Inpatients or ambulatory care patients who had recently received care from a clinical pharmacist at 3 Canadian hospitals were interviewed using a semi-structured interview guide. Thematic analysis using an inductive, semantic approach was performed.

Results: There were 43 participants included and 11 themes identified. The majority of participants desired patient education at any time during hospital visits and participants desired a simplified description of cpKPIs. Participants placed a high level of importance on all cpKPI service delivery throughout their hospital stay because they saw these activities as improving outcomes and quality of life. Participants also reported feeling empowered by participating in the cpKPI feedback process.

For the table that goes with this abstract, please see Abstract Appendix, available at www.cjhp-online.ca/index.php/cjhp/issue/view/119/ show Toc
Conclusions: Participants valued cpKPI-related pharmacist services and participation in the cpKPI feedback process. The results of this study should be incorporated into implementation strategies to improve cpKPI delivery and tracking, support advocacy for clinical pharmacists, and support patient and family-centered care.

\section{Creation and Implementation of a Program-Wide Standardized Clinical Workload Reporting System}

Neilson S, Pereira T, Mysak T

Provincial Operations, Alberta Health Services Pharmacy Services,

Edmonton, $A B$

Background: Our organization had several workload tracking tools that did not meet program requirements as they were disparate across sites, inconvenient to use, and provided delayed, if any, reporting. This limited standard tracking of common measures and prevented reported data from being used to provide feedback to staff regarding their clinical practice.

Description: The objective was to develop and implement a single solution to address these deficiencies and leverage new possibilities. The project was completed in 4 main phases; initial tool development, pilot, roll-out of the tool across the province, and implementation of an engagement program.

Action: As there was no suitable commercially available option, a multi-platform technology (mobile app with parallel web tool) was created. Several workload metrics were selected, including number of activity hours reported, number of patients interactions, and the average time per interaction. Frontline pharmacists served as "SuperUser" site champions to facilitate successful implementation. An engagement program was implemented for leadership to use reports available in "real time" to provide purposeful feedback to staff in discussions about optimizing practice.

Evaluation: Workload reporting significantly improved at the pilot site and is improved overall. Workload capture takes approximately 20 seconds per patient interaction and is estimated to take less than 5 minutes per day. When surveyed, staff describe the tool as "easy to use" and "accessible", and managers report that the engagement discussions with staff have provided insight and opportunity for practice development. The tool is continuously updated to address user provided feedback and changing program needs.

Implications: Clinical workload measures are now easily captured on a single standardized platform and standardly reported across all sites. An engagement program now exists that allows for practice discussions between staff and all levels of leadership. This program has enabled us to standardize work and engage staff in practice development.

\section{Going Beyond the Inpatient Role: An Evaluation of Clinical Pharmacy Services in a Pediatric Outpatient Clinic Setting}

Milicevic T, Ho N

Holland Bloorview Kids Rehabilitation Hospital, Toronto, ON

Background: With the regulation of pharmacy technicians, pharmacists are now better able to explore other areas for clinical intervention and impact. The expansion of clinical pharmacy services from the inpatient role and into a pediatric rehabilitation hospital's outpatient clinic setting was evaluated in this initiative.

Description: The goal of this initiative was to assess the need for clinical pharmacy services among the various pediatric outpatient clinics, pilot pharmacist involvement within one clinic and evaluate impacts on clinical care and the inter-professional team. 
Action: We conducted a needs assessment and individualized consultations with inter-professional staff in order to determine where clinical pharmacy services would be most needed. As a result, the outpatient psychopharmacology clinic was selected for this initiative. A pharmacist was integrated into the inter-professional team for one clinic per week for a 10-month pilot and was involved in new and follow-up consultations. Pharmacist clinical involvement was tracked. Pre and post intervention patient satisfaction surveys and types of medication-related nursing interventions were compared.

Evaluation: During the pilot, the pharmacist was directly involved with $46 \%$ of patients seen in the clinic, including all new referrals to conduct a thorough medication history. The pharmacist identified and resolved 45 drug therapy problems for 61 clients (74\%). Eighty seven percent of patients surveyed indicated that having a pharmacist available to discuss medications was valuable. Clinic staff rated significant additional benefit of a clinical pharmacist's involvement with optimizing medication therapy, resolving drug therapy problems and teaching patients about their medications. Pharmacist involvement correlated with fewer medication-related issues during post-clinic follow up calls conducted by a nurse.

Implications: The results of this initiative demonstrate that integration of clinical pharmacy services into a pediatric outpatient setting can enhance patient care and optimize clinician time. Future evaluations are warranted to assess prioritization of patients for comprehensive pharmaceutical care.

\section{Thrombocytopenia during Treatment with Ceftolozane/Tazobactam}

Oesch $A^{1}$, Dhami $R^{1,2,3}$, Lougheed $C^{1}$, Elsayed $S^{1,2}$

${ }^{1}$ London Health Sciences Centre, London, $O N$

${ }^{2}$ Western University, London, $O N$

${ }^{3}$ School of Pharmacy, University of Waterloo, Kitchener, $O N$

Background: Ceftolozane/tazobactam is a novel ß-lactam/ß-lactamase inhibitor drug combination. When combined with metronidazole for adequate anaerobic coverage, ceftolozane/tazobactam is indicated for the treatment of complicated intra-abdominal infections. Few hematologic adverse effects have been described with this drug in the literature. We report a case of thrombocytopenia during treatment with ceftolozane/ tazobactam.

Case Description: A 50-year-old female presented 4 months postorthotropic liver transplant with a 2 -week history of abdominal pain, malaise, nausea and vomiting. An abdominal computed tomography scan showed radiographic progression of a periumbilical fluid collection and multiple hepatic abscesses. A drain was placed and piperacillin/ tazobactam and tobramycin were initiated. The patient was transferred to the medical-surgical intensive care unit with a decreased level of consciousness requiring intubation post-cardiac arrest. All cultures including blood, peritoneal fluid, and urine were persistently negative throughout her admission. Piperacillin/tazobactam was replaced with ceftolozane/tazobactam in combination with metronidazole to target a multi-drug resistant Pseudomonas aeruginosa based on previous surgical site cultures post-transplant. Laboratory results revealed a platelet count of $142 \times 10^{9} / \mathrm{L}$ at admission and $34 \times 10^{9} / \mathrm{L}$ nearly two weeks later prior to initiation of ceftolozane/tazobactam. Ceftolozane/tazobactam was withdrawn after just 8 doses when the patient showed no signs of clinical improvement and developed worsening thrombocytopenia (platelets $<10 \times 10 \% / \mathrm{L})$ requiring intermittent platelet transfusions.

Assessment of Causality: According to the Naranjo scale, this is a case of possible ceftolozane/tazobactam-induced thrombocytopenia based on a precipitous decline in platelets following the introduction of this agent.
A plausible mechanism is $ß$-lactam induced (hapten mediated) platelet destruction.

Literature Review: While up to $1.9 \%$ of patients receiving ceftolozane/ tazobactam in phase III clinical trials experienced thrombocytosis, this is the first reported case of thrombocytopenia to our knowledge.

Importance to Practitioners: Practitioners should be aware of a possible adverse effect of a novel medication. Ongoing post-marketing surveillance will assist in determining if ceftolozane/tazobactam, in rare cases, causes thrombocytopenia.

\section{Medication Incidents Involving Metformin: A Multi-Incident Analysis}

Liu $M^{1,2}$, Ho $C^{1,2,3}$

${ }^{1}$ Institute for Safe Medication Practices Canada, Toronto, ON

${ }^{2}$ School of Pharmacy, University of Waterloo, Kitchener, ON

${ }^{3}$ Leslie Dan Faculty of Pharmacy, University of Toronto, Toronto, ON

Background: As the mainstay in type 2 diabetes mellitus management and one of the commonly prescribed medications, metformin is used and dispensed frequently in pharmacy practice. Medication incidents involving metformin can either result in sub-optimal management of diabetes or expose patients to the risk of hypoglycemia, calling for attention to such incidents and the need to adopt strategies to improve overall patient and medication safety.

Description: The objective of this multi-incident analysis was to gain a deeper understanding of the possible contributing factors to incidents involving metformin, and to develop potential recommendations to prevent error recurrences.

Action: A total of 403 medication incidents involving metformin were extracted from a national incident reporting database from January to December 2015, with the subsequent performance of a qualitative and thematic analysis on 312 incidents that met the inclusion criteria.

Evaluation: Three main themes were identified from the multi-incident analysis, which included (1) therapeutic role in diabetes management, (2) choice of agent and (3) prescription preparation. Subthemes were further developed for each theme, which included (1) dosing regimen adjustment and maintenance and (2) tablet splitting for "therapeutic role in diabetes management"; (1) drug selection, (2) formulation selection and (3) strength selection for "choice of agent"; and lastly, (1) data entry of prescription and patient care information and (2) blister pack preparation for "prescription preparation".

Implications: With the high usage of metformin, it is hoped that the findings from this analysis and the potential solutions presented can aid with the adoption of error reduction strategies and the building of a safe medication practice environment. Sharing the lessons learned from medication incidents would contribute to overall patient and medication safety.

\section{Managing Warfarin-Rifampin Drug Interaction: A Case Series}

Hooper C, Dool P

London Health Sciences Centre, London, ON

Background: Rifampin is a potent cytochrome P450 (CYP) 2C9 enzyme inducer. As a result, co-administered medications metabolized by $\mathrm{CYP} 2 \mathrm{C} 9$ may require dose adjustments to ensure clinical efficacy. Genomic testing is used to identify an individual's predicted dose and to guide these dose adjustments. 
Case Descriptions: AB is a 73 year-old man prescribed rifampin for a peri-prosthetic joint infection of a total knee arthroplasty, who also requires anticoagulation for atrial fibrillation. $\mathrm{MN}$ is a 66 year-old female with a left ventricular thrombus requiring anticoagulation, who was also prescribed rifampin for a non-TB mycobacterial infection. Genomic testing predicted their warfarin daily doses at $4 \mathrm{mg}$ and $5 \mathrm{mg}$ respectively. Figure 1 demonstrates their International Normalized Ratios (INRs) with corresponding daily warfarin doses and significant events affecting INR.

Assessment of Causality: Both patients required a 3-4 fold increase in expected warfarin doses. At these doses, they achieved near therapeutic INRs. Supra-therapeutic INRs correlated with periods of acute illness and co-administration of antibiotics.

Literature Review: Other case reports echo this difficulty in managing warfarin-rifampin drug interactions. Genomic testing can help guide warfarin dosing based on patient variability in the CYP2C9 and VKORC1 genes.

Importance to Practitioners: This demonstrates the practical experience of genomic testing to guide individualized dosing. Genomic testing also advises the individual's daily dose once rifampin is finished, removing guesswork and avoiding supra-therapeutic INRs. Both cases outline the importance of patient education regarding warfarin especially relating to drug interactions and sick day management.

For the figure that goes with this abstract, please see Abstract Appendix, available at www.cjhp-online.ca/index.php/cjhp/issue/ view/119/showToc

\section{A Prospective Audit of Medication Preparation and Administration Practices: A Quality Improvement Initiative}

\author{
Cicinelli $E^{1}$, Liu $R^{1}$, Saifi $T^{1}$, Lachere ${ }^{2}$, Apio ${ }^{2}$, Cheng $D^{1}$ \\ ${ }^{1}$ Leslie Dan Faculty of Pharmacy, University of Toronto, Toronto, ON \\ ${ }^{2}$ St. Mary's Hospital Lacor, Gulu, Uganda
}

Background: Medication administration errors (MAEs) have important implications for patient safety including increased cost and length of hospitalization, undue discomfort, disability, and death. Patient and medication safety initiatives in low-resource settings may face more barriers than in high-income countries. We aim to describe the baseline frequency and type of errors occurring in a large acute care institution in Uganda.

Description: Implementation of successful interventions to minimize MAEs requires understanding why and how often they occur. Therefore, prospective observation was used to determine the baseline frequency, types, and severity of MAEs.

Action: A data collection tool was created to record details about reconstitution methods, drug, dose, frequency, route and missing doses in the last 24 hours. Data collection was conducted over 2 weeks by 3 pharmacy team members. Any deviation in administration from the order written on the patient's treatment chart was considered to be a MAE. Each drug administration could be associated with none or multiple procedural failures and/or clinical errors. Error rates were calculated using the total number of doses administered as the denominator.

Evaluation: Overall, 530 drug administration events were observed and $101(19 \%)$ had MAEs. The most common type of error was wrong dose (39\%) followed by wrong route (36\%), wrong drug (24\%), and wrong frequency (1\%). Inappropriate technique was observed for $26 \%$ of reconstitutions and 89 drugs had missed doses within the previous 24 hours.
Implications: This audit is part of an interdisciplinary initiative led by the hospital's pharmacy department to improve pharmaceutical care and patient outcomes in a low-resource setting. The results will inform the development of systems and interventions (e.g. educational seminars, annual competency checks, and revised medication administration record) to reduce the occurrence of MAEs. It may also encourage other institutions to incorporate similar processes into their practice to help diminish MAEs.

\section{Relationship between Additional Prescribing Authorization Rates and Work Environment Variables among Clinically Deployed Hospital Pharmacists}

Knyazevych $I^{1}$, Neilson $S^{2}$

${ }^{1}$ Faculty of Pharmacy and Pharmaceutical Sciences, University of Alberta, Edmonton, $A B$

${ }^{2}$ Alberta Health Services, Seventh Street Plaza, Edmonton, $A B$

Background: Additional Prescribing Authorization (APA) legislation was introduced in 2007. Currently $47.2 \%$ of clinically deployed hospital pharmacists (CDHPs) within the organization have APA. The organization's Pharmacy Services program has set a strategic target of $75 \%$ by 2018 . Pharmacy Services endeavours to understand the effect of facility category and municipality size work environment variables, if any, on APA acquisition, to develop and target most effective supportive programming for remaining non-APA CDHPs.

Description: APA status allows pharmacists to independently prescribe schedule 1 drugs at initial access and to manage ongoing patient therapy based on their own patient assessment or in collaboration with other practitioners.

Action: Information regarding APA of actively employed CDHPs was reported by site managers and clinical leaders (CLs) and then compared with province's College of Pharmacists list for accuracy.

Evaluation: Organization's data was analyzed overall and by operational zones for two separate work variables (facility category and municipality size) to determine the relationship between APA rates and two environment variables among CDHPs. $49.1 \%$ of CDHPs working in "Urban" areas have APA versus 37.2\% in "Non-urban" areas, suggesting that pharmacists working in urban municipality sizes are more likely to have APA than those in non-urban environments. $45.7 \%$ of CDHPs working in "Tertiary and Regional" categorized facilities have APA versus $50.3 \%$ in "All Other" facilities, suggesting that pharmacists working in former facility category are less likely to have APA than those in latter facility category. Inconsistent trends between all operational zones suggest that no relationship exists between these two work environment variables and APA rates among CDHPs. Lack of relationship was confirmed by pooled T-Test results ( $\mathrm{p}>0.05)$.

Implications: Knowing that no relationship exists between APA rates and these two work environment variables helps pharmacy managers and CLs better support their staff as they work to achieve the APA designation. 


\section{Review of Immunosuppression Withdrawal after Renal Transplant Failure}

Nijjar $J^{1}$, Kwee $F^{2}$, Narducci $A^{1,2}$

${ }^{1}$ Leslie Dan Faculty of Pharmacy, University of Toronto, Toronto, ON

${ }^{2}$ St. Michael's Hospital, Toronto, ON

Background: Currently, there are no controlled, prospective studies examining the optimal management of immunosuppression after renal transplant failure and return to dialysis. The benefits of maintenance, low dose immunosuppression include: preservation of residual renal function, decreased risk of graft intolerance syndrome or acute graft rejection, reduction in the need for nephrectomy or graft embolization and minimization of allosensitization. However, continued immunosuppression is associated with increased rates of infection and malignancy and the adverse effects associated with chronic corticosteroid use. Due to a lack of data, immunosuppression is withdrawn at the nephrologists' discretion.

Objectives: The main goal was to review primary literature for recommendations on immunosuppression withdrawal after renal transplant failure and to summarize the associated outcomes with the different strategies (infection, transplantectomy, embolization, malignancy and/or mortality).

Methods: A literature search was conducted using Medline and Embase. Key search terms included: wean/withdraw/taper/discontinue/stop, immunosuppression/regimen/protocol, and fail/reject and kidney/renal/ allograft/graft. Studies were included if they evaluated patient outcomes with different immunosuppression regimens after renal graft failure.

Results: Nine observational studies met inclusion criteria. Studies were heterogeneous with different comparator groups and primary outcomes. Five of the 9 studies did not describe the method of immunosuppression taper and the weaning regimens in the remaining studies varied in method and duration. The rate of infection and mortality were greater in groups that continued immunosuppression in all studies that evaluated these outcomes. The rate of transplant nephrectomy was higher in patients weaned off of immunosuppression.

Conclusion: Continuation of immunosuppression following renal graft failure is associated with increased rates of infection and mortality, whereas discontinuation of therapy is associated with higher rates of transplantectomy. The quality of the data is limited by the observational nature of the studies. There is a need for controlled, prospective studies to examine the optimal method of immunosuppression withdrawal after renal graft failure.

\section{Pénuries de médicaments au Canada en 2016 : une problématique toujours d'actualité}

Dubois $S^{1}$, Bussières $J F^{1,2}$

${ }^{1}$ Département de pharmacie et Unité de recherche en pratique pharmaceutique, CHU Sainte-Justine, Montréal, QC

${ }^{2}$ Faculté de pharmacie, Université de Montréal, QC

Contexte : Au cours des dernières années, les pénuries de médicaments ne diminuent pas et nuisent à la prestation sécuritaire de soins de santé.

Objectif : L'objectif était de dresser un portrait de la situation relative aux pénuries de médicaments au Canada en 2016.

Méthodologie : Il s'agit d'une étude rétrospective et descriptive. Une recherche sur PubMed a été menée en utilisant les termes [drug shortages]. Les données de pénuries de médicaments ont été extraites à partir de la liste publiée chaque semaine par McKesson Canada du 31 août 2015 au 4 septembre 2016. Le nombre de pénuries de médicaments, leur classe thérapeutique, la durée moyenne, le nombre et le type de fabricants concernés ont été analysés.

Résultats : Le nombre de publications indexées sur PubMed relatives aux pénuries de médicaments a fortement augmenté depuis 1975 (i.e. un article en 1975 et 96 articles en 2015). Sur la période étudiée, on dénombre 483 médicaments en rupture pour une durée moyenne de $156 \pm 143$ jours. En ordre décroissant d'importance, les médicaments en rupture proviennent des fabricants suivants: Teva $(15,7 \%$; 76/483), Apotex (12,6\%; 61/483), Pharmascience (9,3\%; 45/483), Mylan (7,5\%; $36 / 483)$, Sandoz $(6,4 \% ; 31 / 483)$, etc. Une majorité de médicaments en rupture provient de fabricants de médicaments génériques $(82,6 \%$; $399 / 483$ ) et $27,1 \%$ de ces ruptures ciblent des médicaments administrés par voie parentérale (131/483). Les trois principales classes thérapeutiques des médicaments en rupture sont les médicaments du système nerveux central $(22,4 \% ; 108 / 483)$, les anti-infectieux $(12,2 \% ; 59 / 483)$ et les médicaments cardio-vasculaires (12,2\%; 59/483).

Conclusion : Ces données canadiennes se comparent aux données des années précédentes, signe que la problématique des pénuries de médicaments se chronicise. La publication de ces données canadiennes est essentielle. Plus il y aura de données disponibles, plus le personnel soignant sera en mesure de comprendre la problématique et d'améliorer la gestion de ces pénuries.

\section{Médicaments de niveau d'alerte élevé : profil des stratégies utilisées au sein d'un centre hospitalier universitaire canadien}

Darbon $F^{l}$, Atkinson $S^{1}$, Bussières $J F^{1,2}$

${ }^{1}$ Département de pharmacie et Unité de recherche en pratique pharmaceutique, CHU Sainte-Justine, Montréal, QC

${ }^{2}$ Faculté de pharmacie, Université de Montréal, QC

Contexte : Une pratique organisationnelle requise encadre l'utilisation des médicaments de niveau d'alerte élevé (MNDE) au Canada.

Objectif : Décrire les stratégies utilisées au sein d'un centre hospitalier universitaire canadien pour la gestion des MNDE.

Méthodologie : Il s'agit d'une étude descriptive. À partir des 11 procédures et huit tests de conformité proposés par Agrément Canada, nous avons revu nos pratiques et apporté les changements requis en 2015-2016.

Résultats : Une politique de gestion des MNDE a été établie pour l'ensemble des étapes du circuit du médicament et le rôle de chaque intervenant déterminé. Une liste de MNDE a été également été établie et adoptée, normalisation et limitant les concentrations. L'affichage en ligne (formulaire électronique d'enregistrement des doses de médicaments) et l'étiquetage des médicaments comporte désormais un logo conforme. Une double vérification de la préparation et l'administration de doses de MNDE par le personnel soignant est exigée. Une vérification régulière des stocks de MNDE en pharmacie et dans les services a également été mise en place. Une section dédiée de l'intranet pharmacie a été développée afin d'informer le personnel soignant. Chaque classe thérapeutique de MNDE comporte notamment les risques liés à l'utilisation, les symptômes annonciateurs d'un effet indésirable ou d'un accident, les mesures de prises en charge, les antidotes si applicable, les feuilles d'ordonnances pré-rédigées, des hyperliens utiles et des procédures spécifiques. Une intervention ponctuelle d'information et de formation sur les trois quarts de travail a été effectuée à l'automne 2016. Une courte vidéo de formation a aussi été produite pour le portfolio institutionnel du personnel soignant. 
Conclusion : L'encadrement sécuritaire de l'utilisation de MNDE en établissement de santé requiert de nombreuses stratégies d'intervention. Cette étude description présente l'ensemble des interventions réalisées par l'équipe du département de pharmacie afin de se conformer à la pratique organisationnelle requise.

\section{A Case Series of Patients Using Naloxegol to Reduce Time to Gastrointestinal Recovery Following Surgery}

Khafagy R, Baskette J

London Health Sciences Centre, London, ON

Background: About 4\% of patients develop postoperative ileus (POI) following surgery. Opioids are known to increase gastrointestinal (GI) transit time, which can contribute to POI. Alvimopan is a peripherallyacting mu-opioid receptor antagonist (PAMORA) used to accelerate GI recovery in such patients. However, it may increase the incidence of myocardial infarction (MI) and is only available through the Health Canada Special Access Program. Naloxegol, another PAMORA, has an improved safety and availability profile. There are no trials to describe its use in accelerating time to GI recovery in surgery patients.

Objective: To describe the off-label use of naloxegol in select surgical patients undergoing various abdominal procedures.

Methods: A retrospective review of all patients on general surgery who received at least 1 dose of naloxegol was completed. The efficacy of naloxegol was assessed by tracking patients' total length of hospital stay, time of first stool, and time of first toleration of solid foods following surgery. Safety was assessed by noting adverse events noted in the patient's health record during their hospital stay and in any planned or unplanned encounter afterwards.

Results: Four patients received naloxegol $25 \mathrm{mg}$ orally once daily for an average of 5 days following scheduled abdominal surgery. Patients were 30 to 70 years of age. Average length of hospital stay was 5 days and average time of first stool following procedure was 4 days. Patients tolerated solid foods 1 to 3 days following surgery. Secondary to nausea, 1 patient had a single dose delayed and 1 patient refused 2 doses. No adverse events were noted on post-operative follow-up.

Conclusion: Naloxegol shows promise in reducing the incidence and/or severity of POI. It appears safe, with mild nausea alleviated with anti-emetics being the only adverse event observed. A future randomized controlled trial is being considered to evaluate this off-label use further.

\section{Needs Assessment for Antimicrobial Stewardship in an Acute and Complex Care Hospital Specializing in Orthopaedic Surgery: A Retrospective Descriptive Study \\ Serbanescu $C^{1}$, Walker $S A N^{1,2,3,4^{*}}$, Leis $J A^{3,4,5,6}$ \\ ${ }^{1}$ Leslie Dan Faculty of Pharmacy, University of Toronto, Toronto, ON \\ ${ }^{2}$ Department of Pharmacy, Sunnybrook Health Sciences Centre (SHSC), Toronto, $O N$ \\ ${ }^{3}$ Division of Infectious Diseases, SHSC, Toronto, ON \\ ${ }^{4}$ Sunnybrook Research Institute, SHSC, Toronto, ON \\ ${ }^{5}$ Department of Medicine, SHSC, Toronto, ON \\ ${ }^{6}$ Faculty of Medicine, University of Toronto, Toronto, ON \\ Underlined Author: Pharmacy Student working under supervision of Sandra Walker at time of study (Presenter) \\ * Senior Author; sequence determines credit approach to authorship}

Background: Most antimicrobial stewardship (AS) literature has focused on acute care hospitals, with little known about AS needs in specialized facilities, including complex care.

Objective: To benchmark antibiotic use and identify potential targets for future AS interventions at an acute and complex care orthopedic surgery hospital (ACCOSH).

Methods: A retrospective study was conducted in patients admitted to the ACCOSH between 1January2015 and 31December2015. The metrics were days of antibiotic therapy (DOT)/1000 patient days, frequency of prolonged therapy, identification of most common antibiotics, and number of microbiology cultures processed.

Results: Of 2946 patient admissions, 239 (8\%; 95\%CI:7-9\%) patients were prescribed non-perioperative antibiotics (NPAs) and 2343 (80\%; 95\%CI:79-81\%) were prescribed perioperative antibiotics (PAs). A total of 478/3026 NPA courses were prescribed (16\%; 95\%CI:15-17\%). Cephalosporins (29\%, 137/478), fluoroquinolones (18\%, 88/478), penicillins $(17 \%, 82 / 478)$, and intravenous vancomycin $(6 \%, 31 / 478)$ were the most common NPAs prescribed. Thirty percent of intravenous NPA courses were stepped down to oral therapy $(52 / 171)$. The mean DOT/1000 patient days of NPAs was $241(\mathrm{SD} \pm 65)$, with a median duration of 7 days (IQR 5-9). Although few NPA courses were $>90$ days $(0.4 \%, 2 / 478), 39 \%$ were $>7$ days $(188 / 478)$. A total of $2548 / 3026$ (84\%, 95\%CI: 83-85\%) antibiotic courses were for PAs, where 2240 courses were for cefazolin (88\%, 95\%CI:87-89\%). While urine was the most common culture source received by microbiology $(66 \%$, 961/1454), 24\% (235/961) had no growth. The most common urinary isolate was E. coli (40\%, 57/142). Ciprofloxacin was the most common empiric antibiotic prescribed within 72 hours of urine culture ordering (36/90, 40\%).

Conclusions: AS initiatives targeting use of cephalosporins, fluoroquinolones, penicillins and intravenous vancomycin, duration of therapy, parenteral to oral step down therapy, perioperative antibiotic choice, assessment of urine samples ordered, drawn and processed, and improved empiric prescribing based on a site-specific antibiogram may be beneficial in an ACCOSH.

\section{Development of an Algorithm for a Systematic Evaluation and Classification of Hazardous Drugs}

Ma N, Carating H, Charbonneau F, Iazzetta J, Marchesano R, Mascioli M, Vyas A, Walker SE

Department of Pharmacy, Sunnybrook Health Sciences Centre, and Leslie Dan Faculty of Pharmacy, University of Toronto, Toronto, ON

Background: The National Institute for Occupational Safety and Health (NIOSH) publishes a list of hazardous drugs (HDs) with guidelines to limit occupational exposure. NIOSH classifies HDs into three groups: antineoplastic agents (Group-1); non-antineoplastic agents that meet $\geq 1$ NIOSH criteria for a HD (Group-2); and drugs that pose reproductive risks to men or women trying to conceive or to women who are pregnant or breastfeeding (Group-3).

Description: The objective was to evaluate the evidence for classification of NIOSH listed drugs before adding them to the hospital's HD list.

Action: Available literature and product monographs were reviewed for evidence of occupational risk, allowing development of algorithm for sorting NIOSH 2014 drugs. The algorithm systematically sorts and classifies drugs as HD (pose a risk to all those handling the drug), a Pregnancy/Reproductive Risk drug (pose a risk to pregnant/breastfeeding women or those of reproductive age trying to conceive), or neither of the above. 
Evaluation: The algorithm sorted and classified all NIOSH Group-1 drugs as hazardous, 23 Group-2 drugs as hazardous drugs, 9 Group-2 and 27 Group-3 drugs as Pregnancy/Reproductive Risk drugs, and 6 Group-2 and 10 Group-3 drugs as Non-Hazardous (Figure 1).

Implications: Designating all $2014 \mathrm{NIOSH}$ listed drugs as hazardous may have financial and resource implications for institutions, due to special storage, packaging, labeling and administration requirements. This algorithm systematically identifies drugs with minimal occupational risk that need not be classified as hazardous.

For the figure that goes with this abstract, please see Abstract Appendix, available at www.cjhp-online.ca/index.php/cjhp/issue/view/119/showToc

\section{Long-Term Benzodiazepine Use and Discontinuation: Exploring Hemodialysis Patients' Perspectives}

Cicinelli $E^{1}$, Battistella $M^{1,2}$

${ }^{1}$ Leslie Dan Faculty of Pharmacy, University of Toronto, Toronto, ON

${ }^{2}$ University Health Network, Toronto, ON

Background: Common comorbidities in patients with End-Stage Renal Disease (ESRD) on hemodialysis include anxiety and insomnia, which often result in the use of benzodiazepines. Given the risks associated with chronic benzodiazepine use, such as dependency, withdrawal, rebound symptoms, daytime sedation, falls, and fractures, it is important to understand patient factors contributing to long-term use in this population.

Objective: The objective of the study was to understand patient factors contributing to the chronicity of benzodiazepine use by hemodialysis patients. Identifying these factors could assist in the development of strategies to reduce chronic use in these patients.

Methods: The study consisted of qualitative semi-structured patient interviews. Interviewees were patients in an outpatient hemodialysis unit. Interviews were recorded, transcribed verbatim, and coded using conventional content analysis. Relationships between codes were then identified and synthesized into major themes and subthemes.

Results: A total of 8 patients (median age of 63 years) were interviewed. Analysis of interview data revealed four major themes and five subthemes that describe patients' attitudes and perspectives regarding long-term benzodiazepine use. Two of the major themes encapsulated patient factors contributing to chronic benzodiazepine use: (1) lack of awareness or underestimation of side effects; and (2) challenges associated with dialysis. Two themes capturing patient factors that may enable optimization of benzodiazepine therapy were: (1) awareness of the risk of dependence and addiction; and (2) confidence in healthcare providers.

Conclusions: Findings from this study highlight the scope of the problem of long-term benzodiazepine use by hemodialysis patients. For these patients, a focus on early intervention and prevention of chronic use on the part of health care providers may be more feasible than efforts to taper or discontinue a benzodiazepine after a period of long-term use.

\section{Benzodiazepine and Sedative-Hypnotic Drug Use in Nova Scotia Hospitals: A Point Prevalence Survey \\ Neville $H^{1}$, Losier $M^{1,2,}$, Pitman $J^{1,2,}$ Gehrig $M^{1}$, Isenor ${ }^{2}$, Minard $L^{1}$, Penny $E^{1}$, Bowles $S^{1,2}$ \\ ${ }^{1}$ Nova Scotia Health Authority, NS \\ ${ }^{2}$ College of Pharmacy, Dalhousie University, Halifax, NS}

Background: Benzodiazepines and sedative-hypnotic drugs (BZD/ SHDs), such as zopiclone and the antidepressant trazodone, pose a number of risks such as falls, fractures, and confusion, especially in older adults. Use of these drugs is poorly understood in the acute care setting.

Objectives: To determine the point prevalence and characterize use of BZD/SHDs in Nova Scotia hospitals with $\geq 30$ acute care beds.

Methods: A point prevalence survey (PPS) was conducted by reviewing the health records of adults admitted to hospital between May and August 2016. The number of patients who received a BZD/SHD within the 24 hours prior to the start of the survey was divided by the total number of patients admitted to each ward to determine prevalence. Exclusions were patients $<18$ years of age, drugs given by the intravenous route, and patients in long term care, mental health, addiction treatment, or critical care. Results were summarized descriptively.

Results: All 16 eligible hospitals participated in the PPS. The overall prevalence of BZD/SHD use was 34.6\% (487/1409) and ranged from 15.6-56.3\%. The average age of patients who received a BZD/SHD was 70.3 years, $30.8 \%$ of patients were $\geq 80$ years of age, and $54.6 \%$ of patients were female. The most commonly used drugs included zopiclone (32.0\%), lorazepam $(21.9 \%)$, trazodone $(21.9 \%)$ and clonazepam (11.3\%). Top indications for use were bedtime/daytime sedation $(60.0 \%)$ and anxiety (12.5\%). In $17 \%$ of cases the indication could not be determined. Over half $(55.7 \%)$ of the medications had been initiated at home and continued in hospital, the remainder were started in hospital $(37.6 \%)$, or unknown $(6.7 \%)$.

Conclusions: BZD/SHDs were frequently used by hospitalized patients in Nova Scotia. Areas identified for quality improvement included decreasing the use in older adults, preventing inappropriate initiation of $\mathrm{BZD} / \mathrm{SHD}$ in hospital, and improving the documentation of indications for BZD/SHD use.

\section{What's Happening? Patient Access to Compounded Drugs in Paediatrics after Discharge from a Tertiary Center: A Research Team's Perspective}

Héraut $M K^{1}$, Duong $M T^{1}$, Elchebly $C^{1}, Y u W^{1}$, Kleiber $N^{2}$, Lebel $D^{3}$, Métras $M E^{3}$, Tremblay $S^{3}$, Bussières $J F^{1,3}$

${ }^{1}$ Faculty of Pharmacy, Université de Montréal, Montréal, QC ${ }^{2}$ Department of Paediatrics, CHU Sainte-Justine, Montréal, QC ${ }^{3}$ Pharmacy Department and Pharmacy Practice Research Unit, CHU Sainte-Justine, Montréal, QC

Background: Many commonly used drugs are not commercially available in forms suitable for children. Therefore pharmacies create new compounds by adding excipients to existing adult formulations, often by crushing tablets and creating a suspension. Timely and safe delivery of compounded formulations is challenging but very little is known about the problems faced by patients and their parents with a new prescription of compounded drugs.

Objective(s): To describe issues faced by patients and their parents when obtaining and using a compounded drug.

Methods: This qualitative prospective observational study included patients 0 through 21 years of age who were discharged from a motherchild tertiary hospital with a prescription containing at least one compounded drug between February 2016 and July 2016. Families were called 7 to 10 business days after discharge to complete a telephone follow-up questionnaire. Thereafter, retail pharmacies were contacted to obtain additional information in order to compare the dispensed compounded drug with the prescription and published formulations. Issues identified by the research team were classified according to their real or potential consequences into: none, minor or major. 
Results: Seventy-one patients with a median age of 6.9 months were surveyed. Thus, 99 compounded drugs were included corresponding to 34 different oral drugs. Among a total of 167 issues, 94 were revealed during the interview with parents: 66 issues had minor consequences while 28 had none. The remaining 73 issues involved discrepancies between prescribed and dispensed drug: 70 had minor and 3 had major consequences.

Conclusion(s): A considerable amount of compounded-related issues were identified and most had potential consequences for patients. Therefore, this study suggests current practice standards are insufficient and actions should be implemented to improve compounded drugs dispensation and utilization, especially to ensure patient's safety.

\section{Validation des ordonnances : existe-t-il un ordre optimal ? Avis des chefs de départements de pharmacie}

Dubois $S^{1}$, Atkinson $S^{1}$, Thibault $M^{1}$, Bussières $J F^{1,2}$

${ }^{1}$ Département de pharmacie et Unité de recherche en pratique

pharmaceutique, CHU Sainte-Justine, Montréal, QC

${ }^{2}$ Faculté de pharmacie, Université de Montréal, QC

Contexte : La validation d'ordonnances fait partie des activités essentielles et fondamentales réalisées par le pharmacien. Plusieurs standards de pratique définissent les éléments essentiels à la validation d'ordonnances mais aucun ne précise leur ordre optimal.

Objectif : L'objectif est d'identifier parmi les 22 éléments de validation d'une ordonnance, l'importance et la séquence optimale de ces éléments, par un panel de chefs de département de pharmacie (CDP).

Méthodologie : Il s'agit d'une étude descriptive et prospective. 22 éléments de validation ont été recensés à partir de référentiels. Une enquête en ligne en trois parties a été créée: (1) sélection des éléments de validation selon la présence ou l'absence d'un pharmacien dans les unités de soins; (2) classement des 22 éléments par ordre chronologique; (3) état des lieux des actions de formation et d'évaluation en place dans les départements de pharmacie. Des statistiques descriptives ont été réalisées.

Résultats : Vingt-huit CDP ont participé à l'enquête. En l'absence d'un pharmacien dans les unités de soins, les répondants considèrent 16 des 22 éléments (i.e. $\geq 75 \%$ des répondants par élément) comme étant nécessaires à la validation d'ordonnances. En présence d'un pharmacien dans les unités de soins, les répondants considèrent 12 des 22 éléments (i.e. même condition) comme étant nécessaires à la validation centralisée. Les CDP sont préoccupés par la productivité de la validation d'ordonnances d'où le fait de ne pas prioriser tous les éléments selon les scénarios. Seulement un tiers des CDP ont mis en place des actions de formation et de suivi de performance dans leur département en lien avec la validation des ordonnances de médicaments.

Conclusion : Les CDP ne valorisent pas tous les éléments requis pour la validation d'ordonnance. La mise en place d'une politique et procédure et de programmes de formation à la validation d'ordonnances nous apparaissent nécessaires afin d'encadrer cette activité et d'uniformiser les pratiques.

\section{Comparaison du cadre juridique et des prises de position des agences réglementaires sur les produits biologiques ultérieurs : que doivent savoir les pharmaciens canadiens ?}

Adé $A^{1}$, Pelletier $E^{1}$, Bussières $J F^{1,2}$

${ }^{1}$ Département de pharmacie et Unité de recherche en pratique pharmaceutique, CHU Sainte-Justine, Montréal, QC

${ }^{2}$ Faculté de pharmacie, Université de Montréal, Montréal, QC

Contexte : Un produit biologique ultérieur (PBU) est un produit similaire à un produit biologique de référence. À la différence des médicaments génériques, les PBU présentent une complexité structurale et un processus de fabrication plus complexe.

Objectif : Comparer le cadre juridique et les prises de position des principales agences réglementaires sur les produits biologiques ultérieurs.

Méthodologie : Il s'agit d'une étude descriptive et comparative. Une revue du cadre juridique et des prises de position de quatre agences réglementaires canadienne (Santé Canada), américaine (Food and Drug Administration,FDA), européenne (European Medicine Agency) et française (Agence Nationale de Sécurité du Médicament et des produits de santé,ANSM) a été effectuée. Afin de comparer le cadre juridique et les prises de position, dix variables ont été identifiées: terminologie, définition du PBU et du produit biologique de référence, données non cliniques et cliniques exigées incluant l'immunogénicité, règles de substitution automatique (interchangeabilité), extrapolation de données, nomenclature et pharmacovigilance. Les similitudes et différences ont été identifiées.

Résultats : Seul le Canada utilise le terme PBU; les autres agences préferent le terme biosimilaire. Les quatre agences proposent un cadre juridique semblable. Toutefois, la nomenclature et les règles de substitution automatique different entre les agences. Santé Canada, comme les autres agences, reconnait la biosimilarité mais ne détermine pas l'interchangeabilité. Seules la FDA et l'ANSM envisagent d'offrir un registre confirmant l'interchangeabilité de chaque PBU (permettant la possibilité de substitution automatique par le pharmacien sans consentement du prescripteur). Le "Purple Book" (FDA) et la liste de référence des médicaments biosimilaires (ANSM) sont actuellement en cours d'élaboration.

Conclusion : Les cadres juridiques des quatre agences réglementaires sont semblables. Par contre, il existe des différences dans leurs prises de position. Les pharmaciens doivent connaître les particularités entourant les PBU pour assurer une substitution adéquate.

\section{Development and Validation of a Clinical Decision Tool for Blood Pressure Management in Patients on Hemodialysis}

Ma J, Cameron K, Summa-Sorgini C, Misra P, Richardson R, McQuillan R, Battistella $M$

University Health Network, Toronto, ON

Background: Hypertension is present in up to $70 \%$ of patients undergoing hemodialysis (HD) with less than $30 \%$ of those patients achieving adequate blood pressure control. There are no current guidelines for treating hypertension in this patient population and the evidence available is limited. Management is often complicated as it is multifactorial and must encompass HD specific factors as well as antihypertensive medications. A clinical decision tool would facilitate optimal management of hypertension in this population.

Objective: The primary objective of this project was to develop a clinical decision tool for managing hypertension in patients on HD and to validate the tool through expert review. 
Methods: A literature search was performed to identify existing literature for the treatment of hypertension in patients on HD. Based on the literature findings and through discussion with 3 practicing nephrologists and 1 pharmacist the clinical decision tool was developed. Three rounds of validation of the tool were completed by $15 \mathrm{HD}$ practitioners who completed a questionnaire regarding the tool's face and content validity. The tool was revised after each round of validation based on collected feedback before being presented to the next round of practitioners.

Results: Fifteen practitioners from 5 professions were recruited from 3 institutions for the validation process. The content validity index of the tool was 0.91 after the 3 validation rounds. All HD practitioners who participated in the validation agreed that the tool was understandable, used appropriate wording, and flowed in a logical manner. Eighty-seven percent of participants agreed that they would use the tool in their own practice.

Conclusion: A clinical decision tool for managing hypertension in patients on HD was developed and validated through expert review. Future research will be conducted on implementation of the tool in the $\mathrm{HD}$ unit at our study site and evaluation of patient outcomes.

\section{Compounding of Oral Drugs for Children in a Canadian Pediatric Academic Health Centre}

Carli $A^{1}$, Litalien $C^{1,2,5}$, Sedighi $S^{1}$, Lebel $D^{1,3}$, Théoret $Y^{1,4,5}$, Giroux $D^{1}$, Autmizguine $J^{1,2,5}$

${ }^{1}$ The Rosalind \& Morris Goodman Family Pediatric Formulations Centre of the CHU Ste-Justine, Montréal, QC

${ }^{2}$ Department of Pediatrics, Université de Montréal, Montréal, QC

${ }^{3}$ Department of Pharmacy, CHU Ste-Justine, Montréal, QC

${ }^{4}$ Department of Biochemistry, CHU Ste-Justine, Montréal, QC

${ }^{5}$ Department of Pharmacology, Université de Montréal, Montréal, QC

Background: Many medications given to children have no commercially available pediatric oral formulations. This leads to manipulation of dosage forms designed for adults and increases the risk of dosing error, exposure to unsafe excipients, and therapeutic failure in children. The scope of this problem is not well characterized.

Objectives: 1) To describe which drugs require compounding for oral administration in children. 2) For each compounded drug, to compare regulatory status, and availability of pediatric oral formulations across different countries.

Methods: We retrospectively reviewed drugs requiring compounding for oral administration. We included drugs that were compounded 1) at a Canadian pediatric academic health centre, or 2) out of the hospital from the list of drugs reimbursed by a provincial public insurance in $\geq 100$ occasions over 1 year. Compounding was defined as 1) the preparation of an extemporaneously compounded oral liquid formulation in-andout of hospital, or 2) tablet splitting in-hospital. Each drug was classified according to its regulatory status, and availability of commercialized oral formulations in Canada, the United States and European Union.

Results: A total of 98 drugs required compounding. Of those, 78 and 57 were prepared in a liquid form in-hospital, and out-hospital, respectively; and 18 required tablet splitting in-hospital. Of 98 compounded drugs, $39(40 \%)$ have commercially available pediatric formulations in the US or Europe (Table 1). Of 63 compounded drugs with no pediatric indication, 30 (48\%) have a pediatric indication outside of Canada.

Conclusion: These results suggest significant variability in regulatory status of compounded drugs. This work will be used to elaborate a strategy to improve access to commercially available pediatric formulations for Canadian children.
For the table that goes with this abstract, please see Abstract Appendix, available at www.cjhp-online.ca/index.php/cjhp/issue/view/119/ show Toc

\section{Optimizing Proton Pump Inhibitor Therapy in Primary Care: A Pilot Study Evaluation of a Patient Directed Intervention}

\author{
Richardson $L^{1}$, Kwan $D^{2}$, Marr P2, Papoushek $C^{2}$, Walsh $K^{3}$, Lyon $K^{2}$ \\ ${ }^{1}$ Rideau Family Health Team, Ottawa, ON \\ ${ }^{2}$ Toronto Western Family Health Team, Toronto, ON \\ ${ }^{3}$ Toronto Central Community Care Access Centre, Toronto, ON
}

Background: Patients frequently receive proton pump inhibitors (PPIs) for an extended duration of time without regular reassessment. Previous studies have focused on reducing inappropriate PPI use in patients who have been on therapy for extended durations. However, there is limited evidence about the effectiveness of interventions aimed at optimizing treatment duration in patients newly started on PPI therapy.

Objectives: 1. Determine whether a patient handout provided at the outset of therapy facilitates the tapering and stopping of newly prescribed PPIs after the appropriate treatment period. 2. Describe the patient's perspective related to the tapering and stopping of PPIs. 3. Determine the patient's reported satisfaction with the patient handout.

Methods: This was a prospective, one-arm, open label cohort pilot study. Included patients were $\geq 18$ years of age who were newly prescribed a PPI for gastroesophageal reflux disease, endoscopic negative reflux disease, or esophagitis grade $\mathrm{A}$ or $\mathrm{B}$. The intervention was a handout provided to patients at the outset of their treatment. The handout outlined the risks of long-term PPI use, provided a tapering schedule and discussed non-pharmacological management strategies for symptom control. Outcomes were assessed using a follow-up telephone survey at 6 weeks.

Results: In total, 6 patients completed the study. At the end of the six-week follow-up period, $66.6 \%$ of patients $(n=4)$ successfully tapered off their PPI without significant increases in symptoms. On average, participants rated the importance of stopping their PPI as a 9 out of 10 and overall expressed good satisfaction with the patient handout.

Conclusion: This patient-directed intervention targeting those newly started on PPIs can safely reduce PPI use after the recommended treatment period. This pilot study supports further research to assess the impact of the patient-directed handout on the tapering and stopping of PPIs.

\section{Stability of 10 and $50 \mathrm{mcg} / \mathrm{mL}$ Fentanyl Solutions in CADD $\otimes$ Reservoirs, PVC Containers and Ethylene/Propylene Co-Polymer (PAB $®)$ Bags at Refrigerated $\left(4^{\circ} \mathrm{C}\right)$ and Room Temperature $\left(23^{\circ} \mathrm{C}\right)$}

Law S, Perks W, Iazzetta J, Walker SE

Department of Pharmacy, Sunnybrook Health Sciences Centre, and Leslie Dan Faculty of Pharmacy, University of Toronto, Toronto, ON

Background: Publications have demonstrated the stability of fentanyl solutions for up to 30 days in cassettes. We sought to evaluate the interaction of chemical stability and water loss on the actual concentration in several containers.

Objective: To evaluate the stability of fentanyl 10 and $50 \mathrm{mcg} / \mathrm{mL}$ solutions and water loss over 90 days at room temperature and refrigerated conditions in CADD reservoirs, PVC bags, and PAB $®$ bags. 


\section{PPC 2017 POSTER ABSTRACTS / RÉSUMÉS DES AFFICHES DE LA CPP 2017}

Methods: On study day 0, 4 units each of $100 \mathrm{~mL}$ solutions of fentanyl $10 \mathrm{mcg} / \mathrm{mL}$ were prepared in sodium chloride $0.9 \%$ (NS) and 50 $\mathrm{mcg} / \mathrm{mL}$ were added to CADD reservoirs, PVC bags, and PAB® bags. Concentration, physical inspection and bag weights were completed on days $0,1,4,7,14,21,35,56,70$, and 90 . Fentanyl concentrations were determined by a validated stability-indicating liquid chromatographic method with UV detection. Chemical stability was based on the intersection of the lower limit of the $95 \%$ confidence interval of the observed degradation rate and the time to achieve $90 \%$ of the initial concentration after correction for water loss.

Results: The analytical method measured fentanyl concentrations specifically, accurately (deviations averaged $2.44 \%$ ), and reproducibly (replicate error of $1.0 \%(\mathrm{CV} \%)$. During the study, water loss was apparent in PVC and CADD reservoirs increasing concentrations by $6 \%$ at room temperature. When corrected for water loss, the average concentration varied by less than $2.53 \%$ over the 90 -day period and solutions retained a concentration within $6.45 \%$ of the initial, with $95 \%$ confidence. Chemical stability exceeded 90 days for all containers.

Conclusions: We conclude that fentanyl concentrations of 10 and $50 \mathrm{mcg} / \mathrm{mL}$ are physically and chemically stable for at least 90 days at room temperature $\left(23^{\circ} \mathrm{C}\right)$ or refrigerated $\left(4^{\circ} \mathrm{C}\right)$ in PVC bags, CADD reservoirs and $\mathrm{PAB}$ containers. Water loss may limit the beyond-use-date on PVC bags and CADD reservoirs during room temperature storage.

\section{Applying the Proton Pump Inhibitor Deprescribing Algorithm in Stable Patients in a Community Hospital}

Wang S, Lee M

North York General Hospital, Toronto, ON

Background: The Canadian Deprescribing Network (CaDeN) published an evidence-based algorithm to help clinicians reduce the inappropriate use of proton-pump inhibitors (PPI). Application of this algorithm in stable hospitalized patients has not been studied previously.

Objectives: To evaluate the success rate of deprescribing PPI in patients designated alternate level of care (ALC) at a community teaching hospital by applying the deprescribing algorithm.

Methods: Between Mar $1^{\text {st }}$ and May 31 $31^{\text {st }}, 2016$, the pharmacist reviewed all patients transferred to the unit on a PPI, applied the PPI deprescribing algorithm and made recommendations to the physicians. All patients intervened on were monitored until discharge or at 3 months whichever came first, for relapse of symptoms or if PPI had to be resumed. The proportion of patients who had their PPI successfully discontinued or reduced at the end of the follow-up period was calculated.

Results: Twenty-eight of 72 (39\%) ALC patients with a mean age of 80.9 years were on a PPI. The most common indication was gastroesophageal reflux disease (GERD). Deprescribing recommendations were made in 20 patients $(71 \%)$ who met the criteria outlined in the algorithm. Sixty percent of the recommendations were accepted, which resulted in PPI discontinuation in 10 patients and dose reduction in 2. Deprescribing recommendations were not accepted in patients with dementia where symptoms assessment was challenging, and in those receiving enteral tube feeding or antithrombotic therapy due to the perceived needs for gastroprotection. Two patients who had their PPI discontinued eventually resumed therapy due to suspected upper gastrointestinal reflux symptoms.

Conclusions: Discontinuation or dose reduction of PPI can be achieved in stable hospitalized patients by applying the PPI deprescribing algorithm. Additional direction to help guide deprescribing PPI in patients who receive therapy for gastroprotection is needed. 